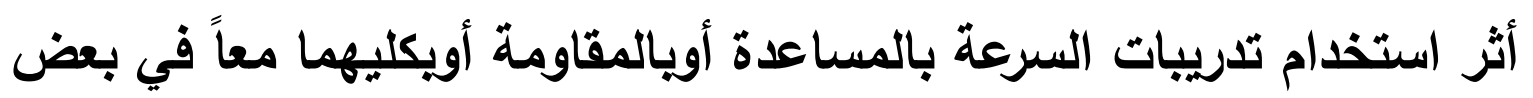

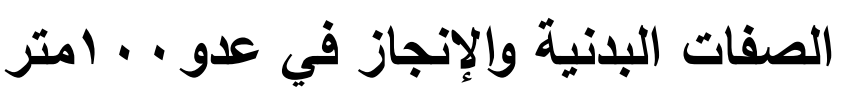

\author{
م.م معن عبدالكريم جاسم \\ أ. أ.م.د اياد محمد عبدالله
}

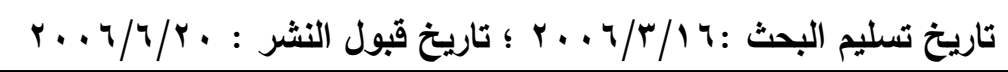

\section{ملخص البحث}

يهرف البحث الكثف عن أثر استخدام تدريبات السرعة بالمساعدة وتدريبات السرعة بالمقاومـة وتدريبات

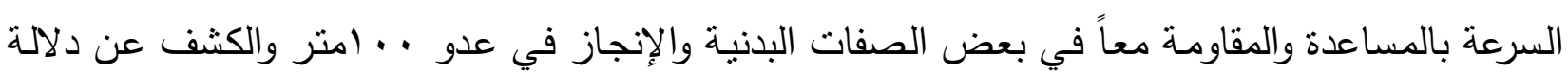
الفروق الإحصائية في بعض الصفات البدنية والإنجاز في عدو . (متر بين تدريبات السرعة بالمساعدة

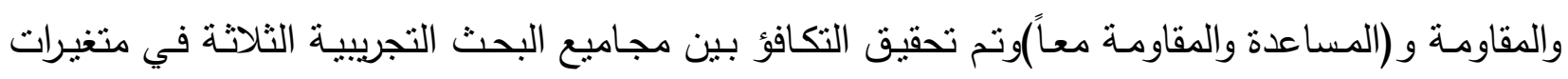
(العمر ، والطول، والوزن) وبعض الصفات البدنية وهي (السرعة الانتقالية القصوى ، والقوة الانفجارية للرجلين

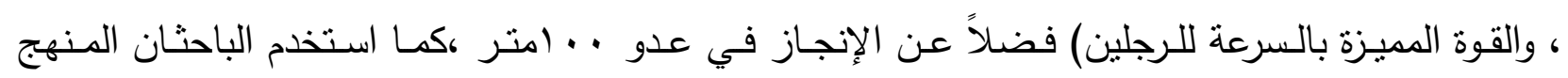

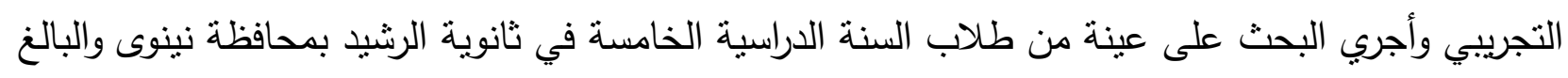

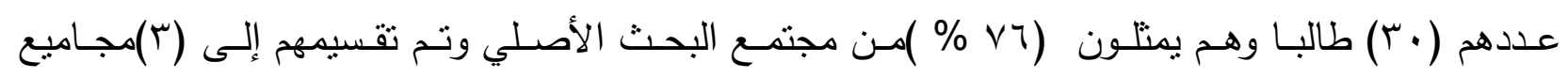

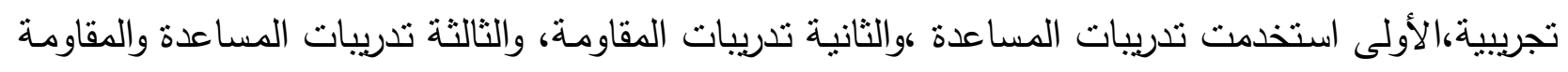

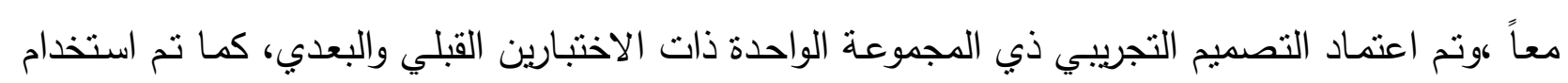

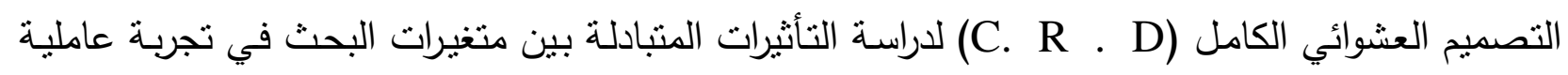

وتوصل الباحثان إلى الاستتتاجات الآتية:

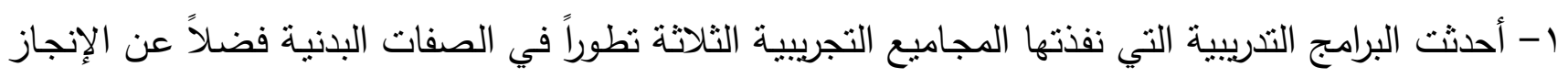

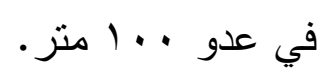
ץ- أحدث البرنامج التدريبي الذي نفذته المجموعة التجريبيـة الثالثة الذي تضمن تدريبات السرعة بالمساعدة

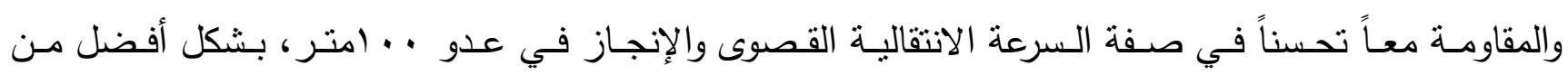
المجموعتين الاخرتين. 
r- أحدث البرنامج التدريبي الذي نفذته المجموعة التجريبية الثالثة الذي تضمن تدريبات السرعة بالمساعدة والمقاومة معاً في الاختبار البعدي تفوقاً في صفة القوة الانفجارية للرجلين، وجاءت بالمرنبة الثانية المجموعة الثانية في حين حلت المجموعة الأولى بالمرتبة الثالثة. ع - أحدث البرنامج التدريبي التي نفذته المجموعة التجريبية الثالثة التي تضمنت تدريبات السرعة بالمساعدة والمقاومة تطوراً في صفة القوة المميزة بالسرعة للرجلين على الرغم من أن هذا التطور لم يرتق إلى مستوى

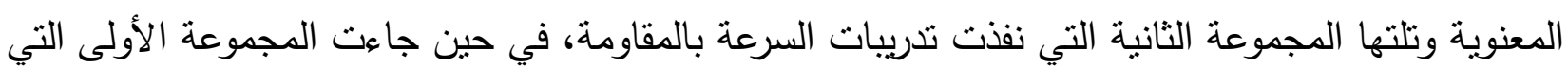
نفذت تدريبات السرعة بالمساعدة بالمرتبة الثالثة.

\title{
Effects of Using Sprint Trainings by Aids, Resistance and both on some Physical Components and Performance of 100 meters Dash
}

\author{
Dr. Eyad Mohammed Abdullah Maan Abdul kareem Jasim \\ University of Mousl - College of Sport Education
}

\begin{abstract}
The research aims at being acquainted with effects of using sprint training by aids, resistance and both on some physical components and performance of (100) meters dash in addition to the significance in some physical components and performance of (100) meters dash among three methods. The equality among groups was achieved in variables of age, high, weight and some physical components such as maximal locomotive sprint, explosive strength of legs and strength in addition to the performance of 100 meters dash

The experimental methodology was used. The sample included (30) students of fifth class in Al-Rashid secondary school which represents $(76 \%)$ of research society. The design of one group with pre and post tests was applied in addition to the C.R.D design to study the alternative effects among variables of research in factorial experiment $(2 \times 4)$.

The sample divided into (3) groups. The first one applied the sprint training by aids. The second one applied the sprint training by resistance. The third one applied the sprint training by aids and resistance.
\end{abstract}

The research concluded the following: 
1- All programs achieved an improvement in physical components and performance of (100) meters dash.

2- The program of The third group applied the sprint training by aids and resistance achieved an improvement in maximal locomotive sprint and performance of (100) meters dash better than other groups.

3- The program of The third group applied the sprint training by aids and resistance achieved an improvement in the explosive strength of legs better than other groups. The second group came in the second order while the first group came in third order

4- The program of The third group applied the sprint training by aids and resistance achieved an improvement in the strength of legs in spite of there were no significant differences. The group applied the sprint training by resistance came in second order and the group applied the sprint training by aids came in third order.

\section{1-التعريف بالبحث \\ 1-1 المقدمة والهمية البحث}

من المعلوم إن كافة البرامج التدريبية يجب أن تبنى لتحقيق تتمية شاملة للقدرات البدنية والوظيفية المطلوبة

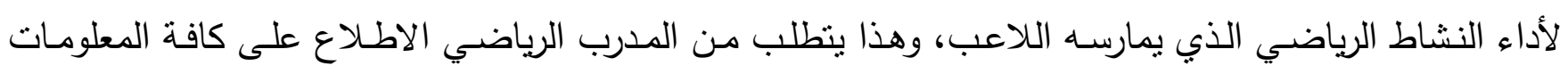

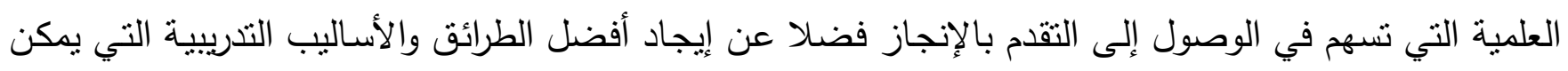

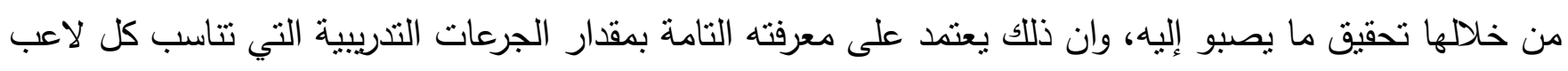

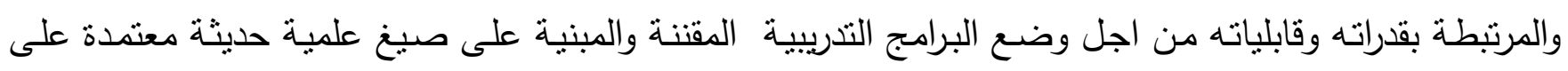

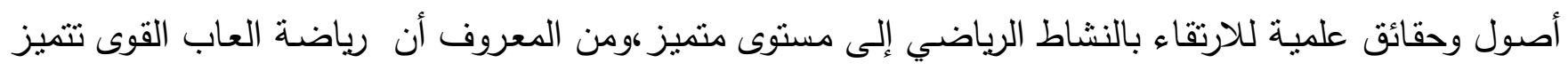

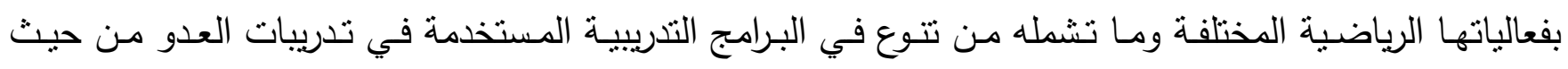

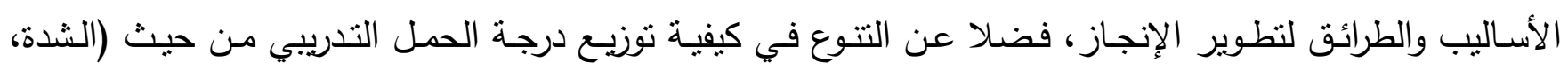

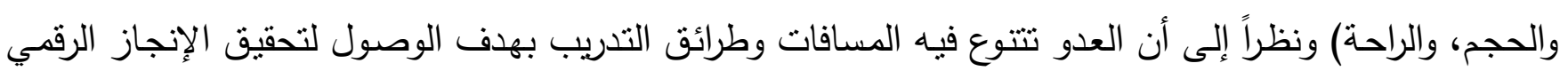

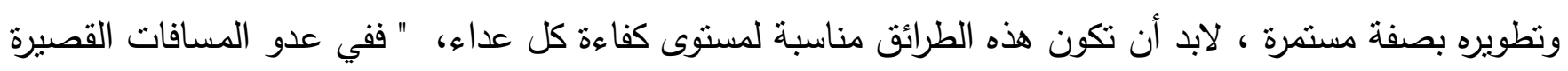

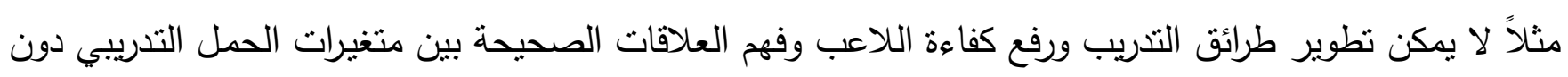

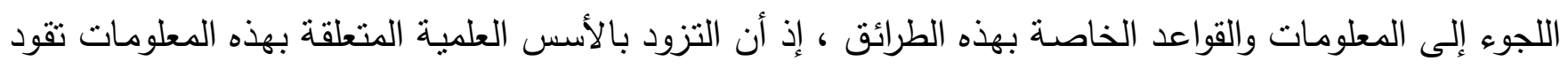

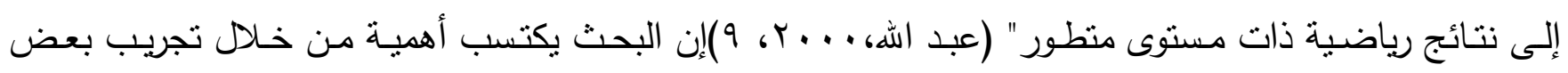

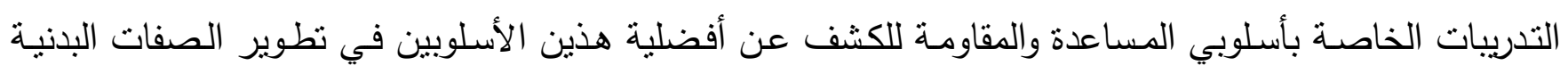

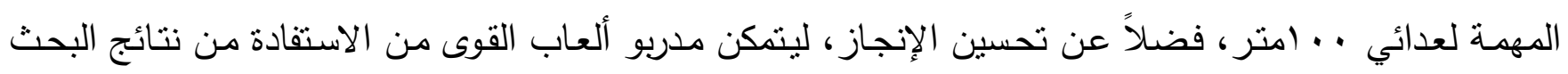


والوقوف على مدى صلاحية كل أسلوب من هذه الأساليب، لآن هذا بدوره يؤدي إلى التخطيط العلمي السليم للبرامج

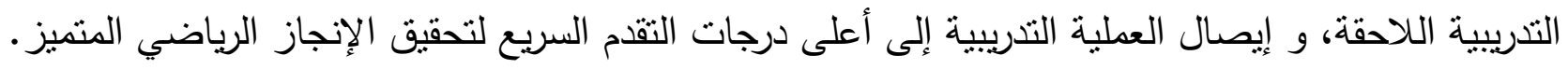

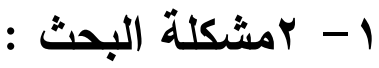
لقد اهتم الباحثون والمدربون الرياضيون بتطوير وتحديث أساليب التدريب الرياضي لتكون مؤثرة وفعالة بشكل اكبر

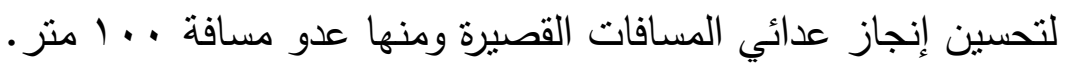

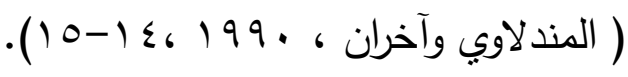

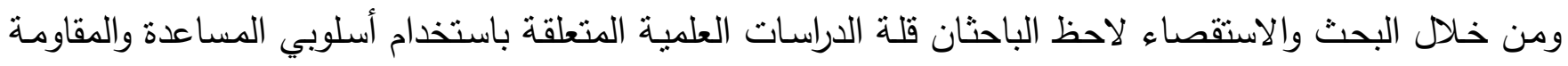

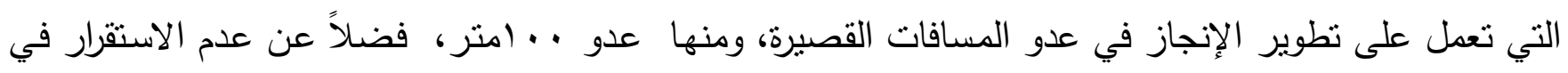

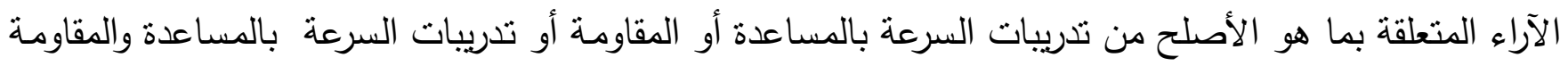

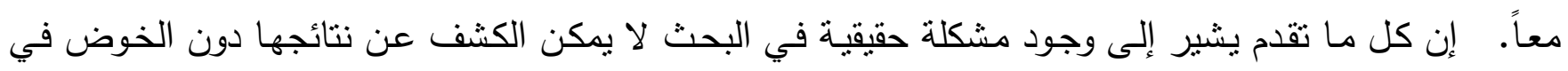

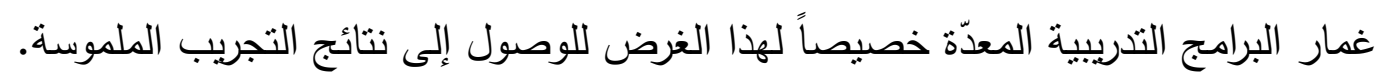
لذلك فإن مشكلة البحث تتحدد في النساؤلات الآتية: هل أن تطوير الانجاز في عدو .أمتر يتم عن طريق استخدام تدريبات السرعة بالمساعدة فقط ؟

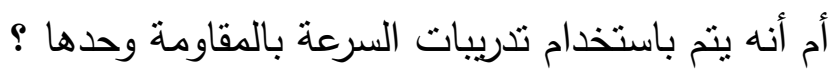

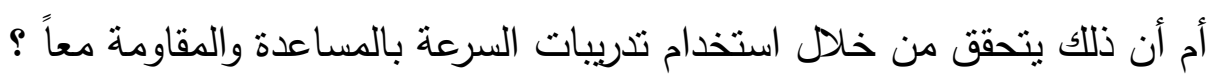

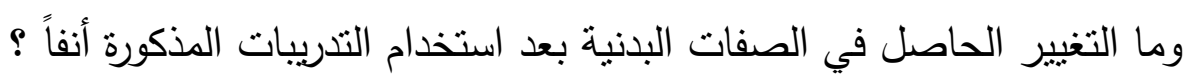
ا *قأثر استخدام تدريبات السرعة بالمساعدة في بعض الصفات البدنية والانجاز في عدو . المتر بين الاختبارين القبلي والبعدي. *أثر استخدام تدريبات السرعة بالمقاومة في بعض الصفات البدنية والانجاز في عدو .. (متر بين الاختبارين القبلي والبعدي. * أثز استخدام تدريبات السرعة بالمساعدة والمقاومة معاً في بعض الصفات البدنية والانجاز في عدو .. امتر بين الاختبارين القبلي والبعدي.

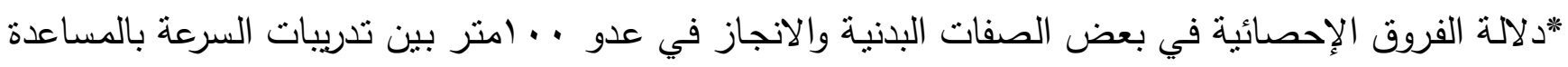
والمقاومة و (المساعدة والمقاومة معاً).

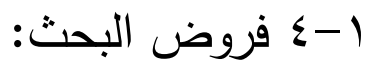
"وجود فروق ذات دلالمة معنوية في بعض الصفات البدنية والانجاز في عدو . امتر بين الاختبارين القبلي والبعدي بعد تتفيذ تدريبات السرعة بالمساعدة ولصالح الاختبار البعدي. 
"وجود فروق ذات دلالمة معنوية في بعض الصفات البدنية والانجاز في عدو .. امتر بين الاختبارين القبلي والبعدي بعد تتفيذ تدريبات السرعة بالمقاومة ولصالح الاختبار البعدي.

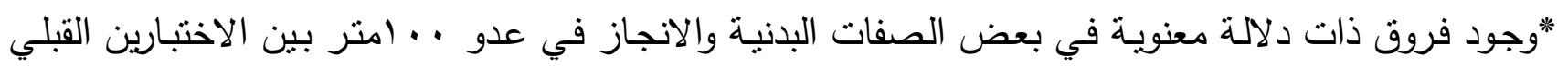

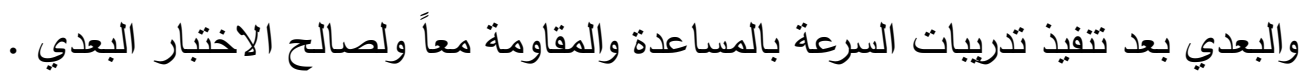

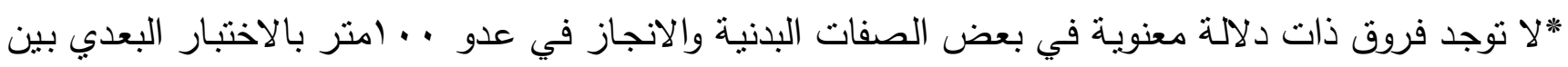
مجاميع البحث.

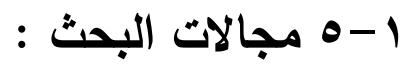

* المجال البشري: طلاب السنة الدراسية الخامسة في ثانوية الرشيد بمحافظة نينوى.

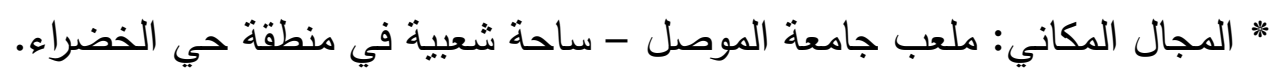

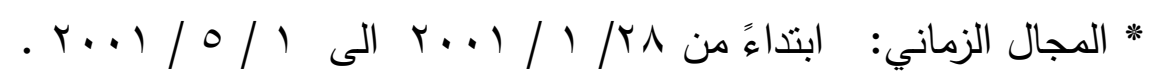
r- r الدراسات النظرية والدراسات المشابهة: r- r-

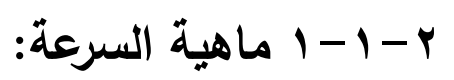

تعد السرعة واحدة من بين أهم الصفات الرئيسة للياقة البدنية، وهي ذات أهمية بالغة في ممارسة معظم أنواع الأنشطة

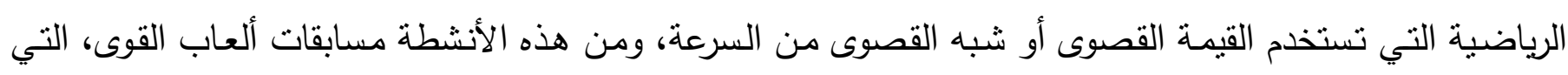

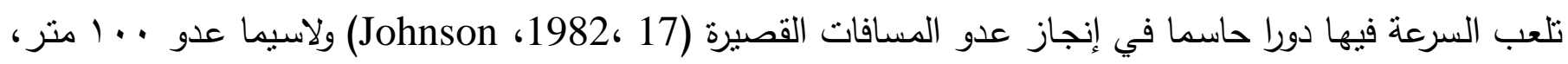

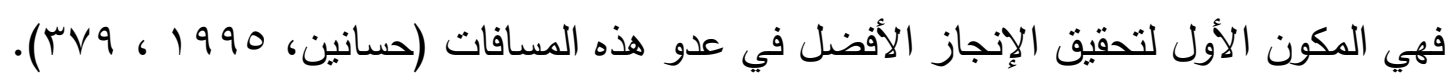
r- r- r أساليب تطوير السرعة:

أن صفة السرعة هي الصفة المؤثرة والمتحكمة في المستوى في سباقات عدو المسافات القصيرة، لذلك يجب أن أن تشتمل

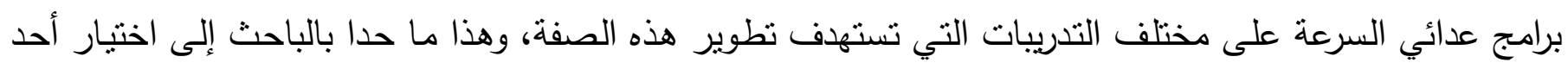

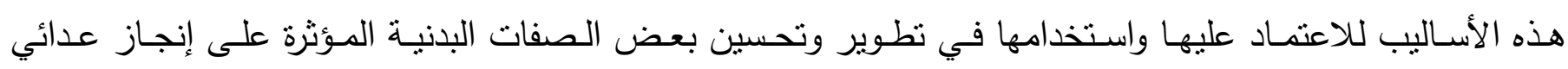

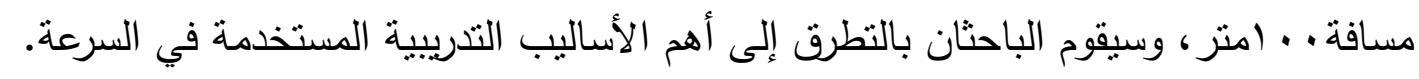

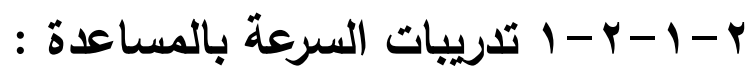
وتسمى تدريبات السرعة العاليـة، إذ تساعد هذه التدريبات على العدو بسرعات اكبر من السات السرعات في السباقات

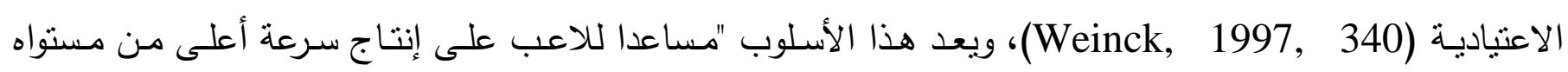

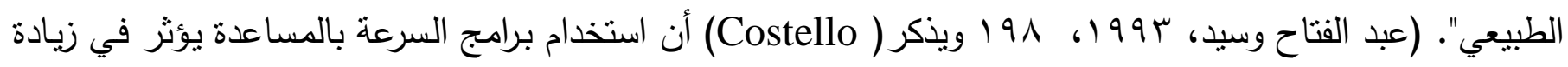

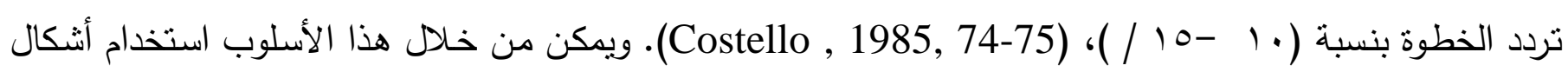


متتوعـة من التدريب لزيـادة السرعة وهي(العدو نزولا مـن منحدر، سحب اللاعب بالحبل المطاطي،سـب اللاعب الميكانيكي،الاستفادة من سرعة الريح،استخدام الثريط الدوار ).

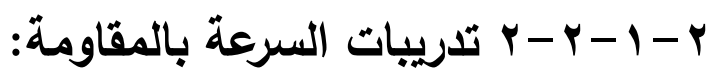

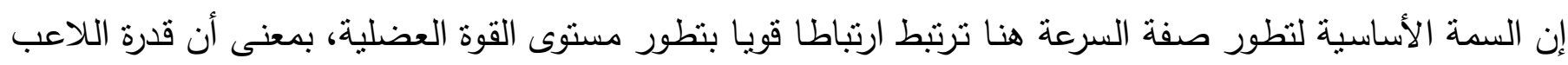

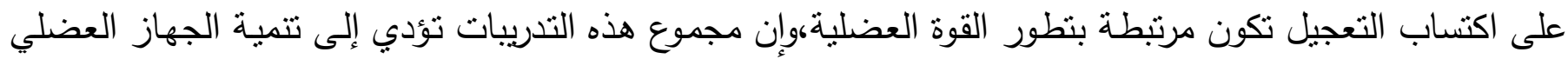

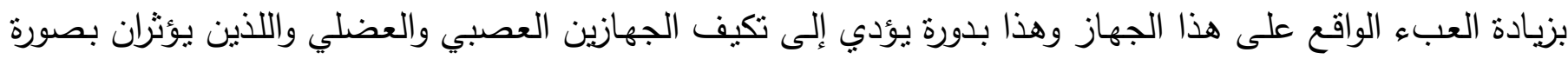

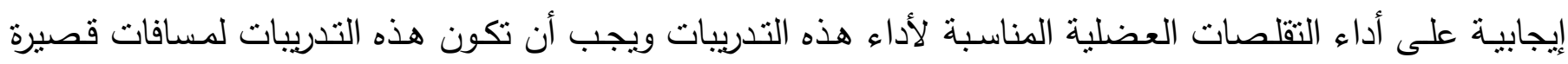
وبجهد مناسب لمسنوى اللاعبين • (Hubiche \& Pradet , 1993, 55) وهناك أنثكال عديدة لتدريبات السرعة بالمقاومـة وهـي(العدو لصعود منحدر ، العدو مـع سـب مقاومـة، العدو على الأراضـي الرخوة،العدو عكس اتجـاه الريح،العدو في المياه الضحلة،مظلة السرعة،العدو فوق المدرجات).

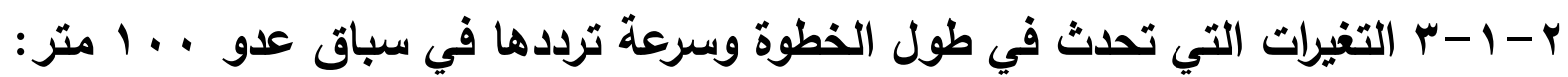

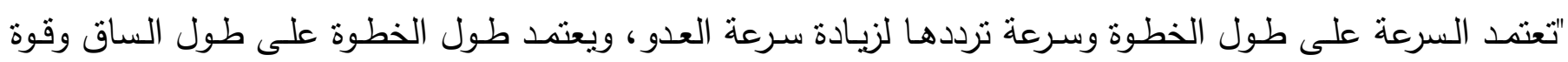

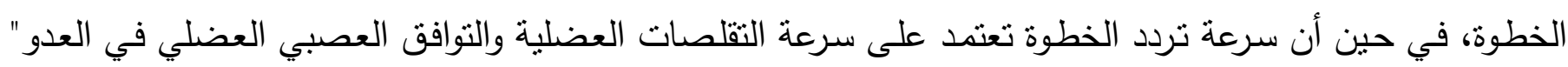
(Clayne et al, 1986 , 298)

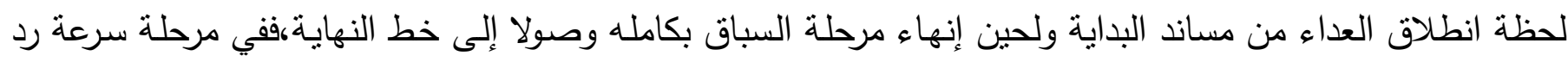

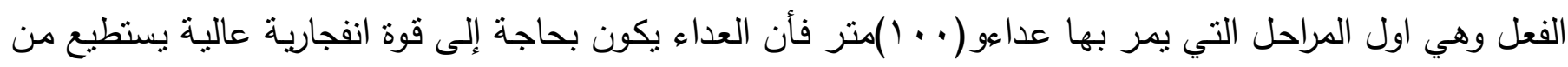

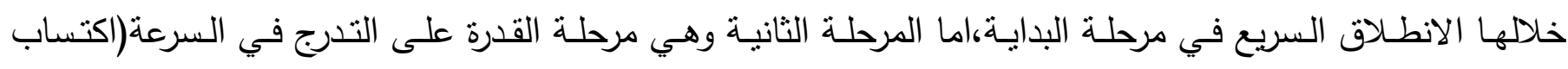

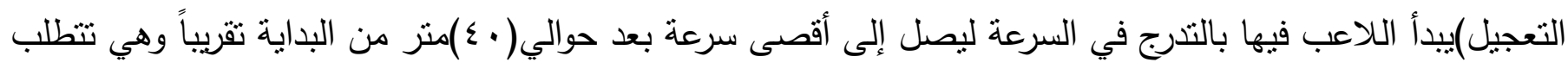

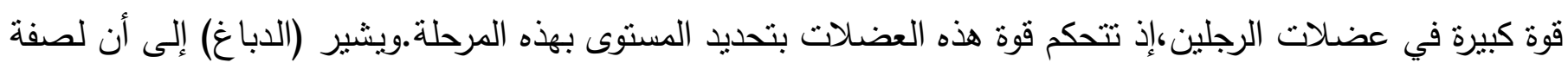

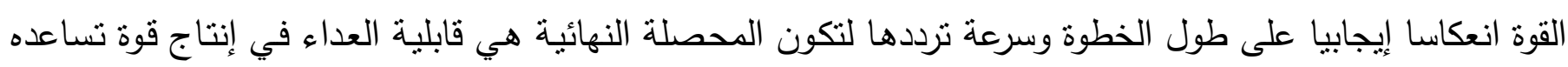

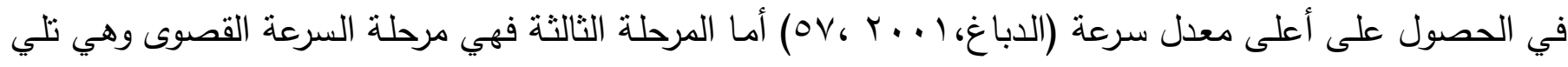

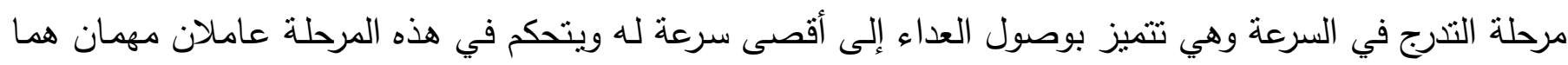

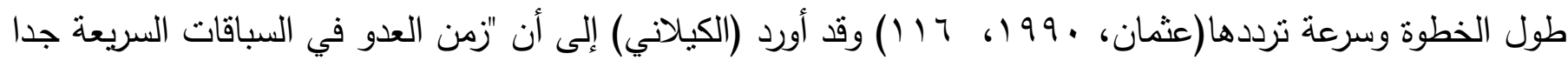

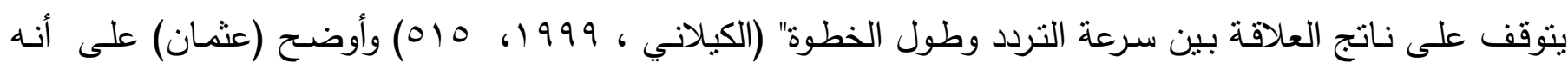

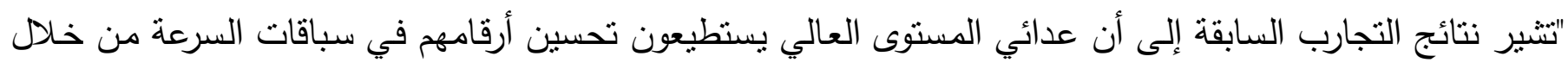

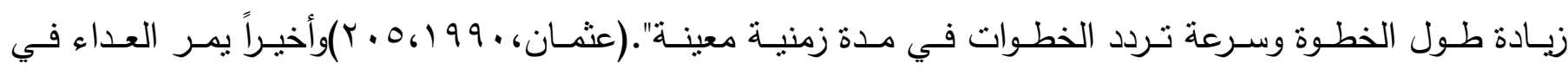

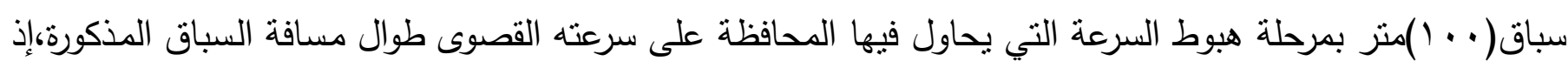

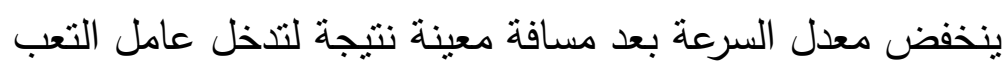




\section{(Modamgha, 1986)}

تأثير برامج النتريب المتتوع لركض المرتفع وركض المنخفض وركض المرتفع والمنخف وركض المستوي على السرعة القصوى لمسافة (·r) متراً.

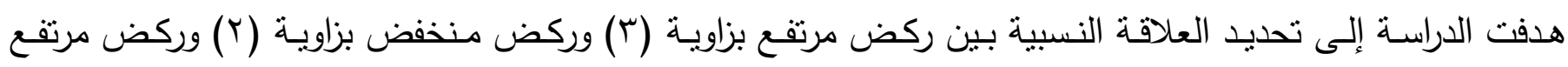

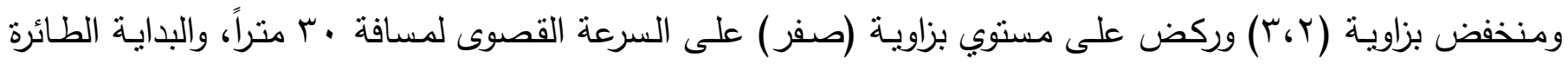

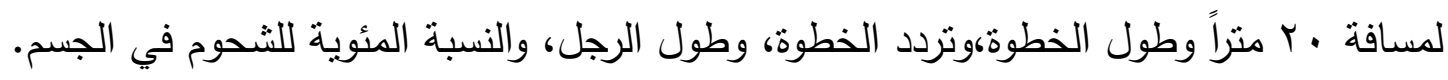
وأجريت الدراسة على عينة مكونة من (.0) طالبا من طلاب السنة الدراسية الأولى في كلية التربية الرياضية، جامعة العادية

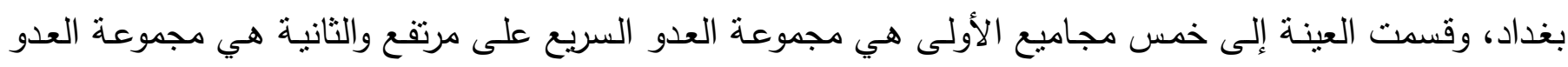

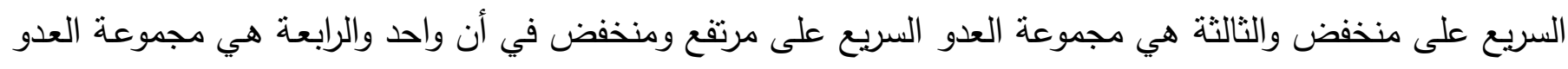

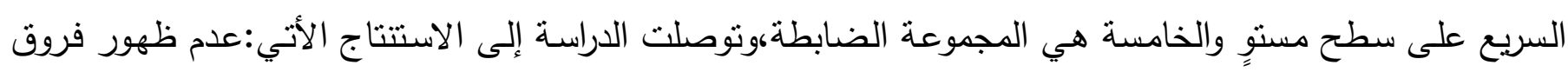

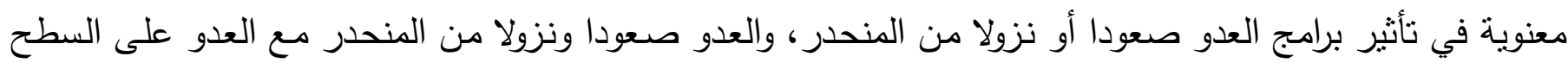

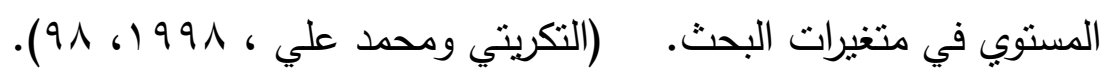

r-r-r التحليل الكينمانيكي لطول وتردد الخطوة في أثناء الجري على السير النتحرك مختلف الستتوى والسرعة.

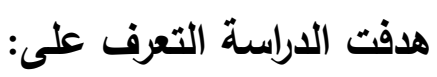

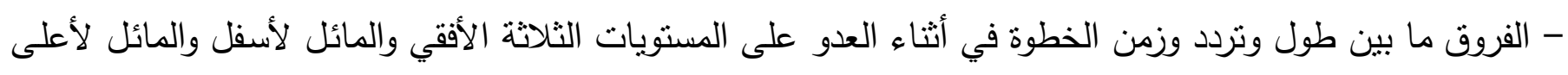

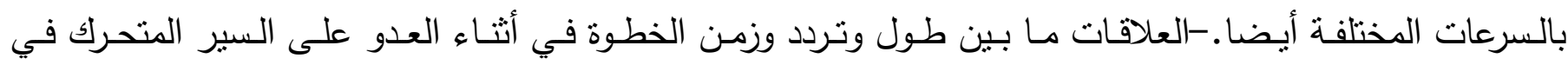
المستويات الثناثة وخلال السر عات المختلفة.

وتكونت عينة الدراسة من (• () ذكور من عدائي المنتخب الوطني الإماراتي للمسافات المتوسطة والطويلة، إذ تم اختيارهم بطريقة عددية في مركز تجمع تنريبهم في إمارة دبي. 


\section{وتوصلت الدراسة إلى الاستتناجات الآتية:}

- وجود فروق ذات دلالة إحصائية في متغيرات تردد الخطوة ، وطول الخطوة ، وزمن الخطوة، ومعدل تردد الخطوة وذللك ما بين العدو على المستوى الأفقي والمائل لأسفل.

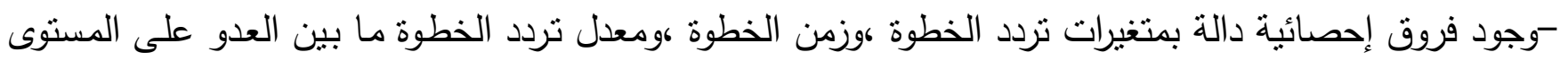
المائل لأعلى والأفقي،وما بين العدو على المستوى المائل لأسفل والمستوى الأفقي. (الكيلاني، (999)

$$
\text { r- ب- إجراءات البحث: }
$$

استخدم الباحثان المنهج التجريبي لملاءمته لطبيعة البحث.

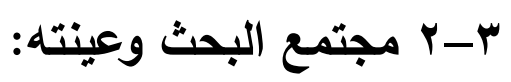

بعد أن حدد الباحثان مجتمع البحث بطريقة عمدية بطلاب السنة الدراسية الخامسة في ثانوية الرشيد بمحافظة نينوى

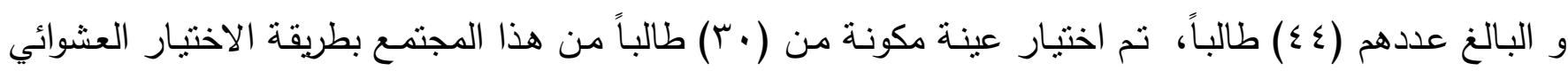

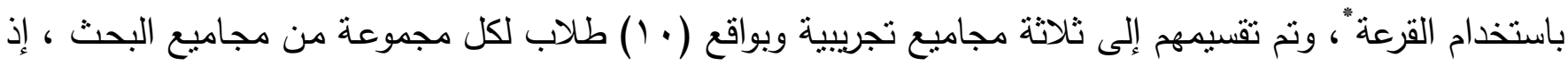

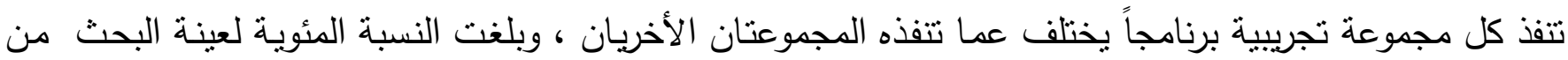

$$
\begin{aligned}
& \text { مجتمع البحث الكلي (ד V \%). } \\
& \text { r-r تكافؤ مجاميع البحث: }
\end{aligned}
$$

تم إجراء التكافؤ بين مجاميع البحث الثلاثة المختارة على وفق المتغيرات التي تم اعتمادها في البحث والتي شملت

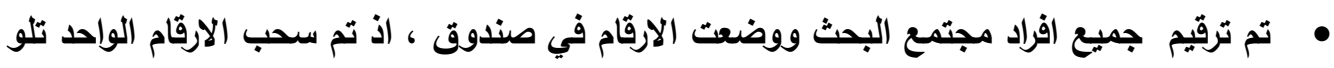
الاخر ولحين استكمال العدد المطلوب لمجاميع البحث قيد البحث. 
(بعض الصفات البدنيـة والإنجـاز في عدو . 1 متـر)، وتم اختبـار هذه الصفات مـن قبـل السادة ذوي الخبـرة

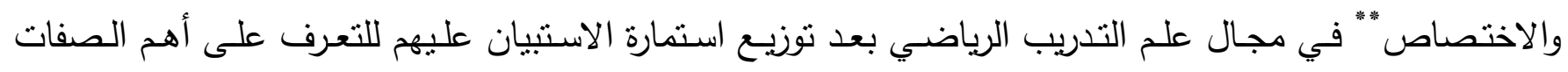

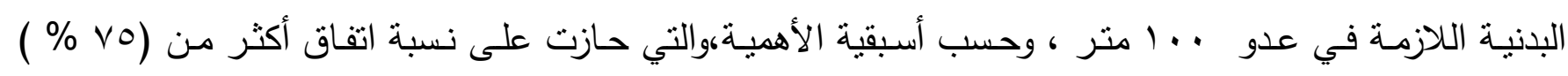
وكانت هذه الصفات (السرعة الانقالية القصوى ، والقوة الانفجارية للرجلين ، والقوة المميزة بالسرعة للرجلين).

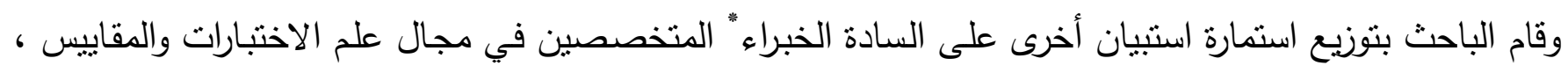

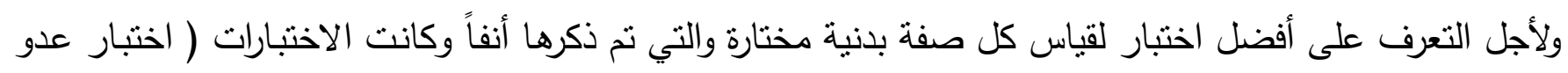

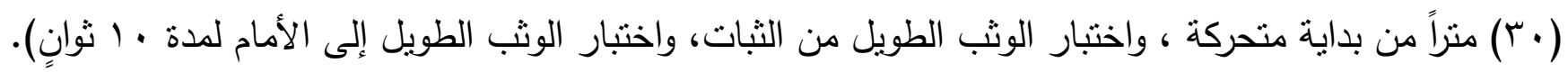

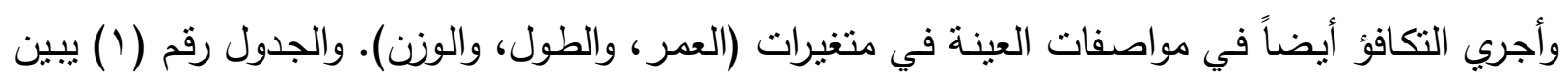
الأوساط الحسابية والانحرافات المعيارية للمتغيرات المعتمدة في التكافؤ.

(1) (1) (1)

“* السادة ذوي الخبرة والاختصاص في مجال علم التدريب الرياضي:

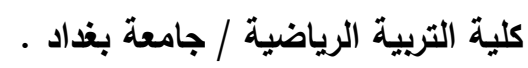

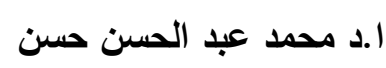

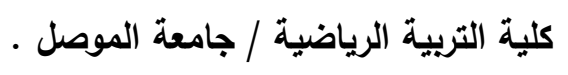

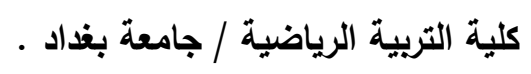

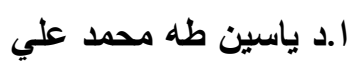
كلية التربية الرياضية / جامعة الموصل. ا.د رعد جابر باقر طي الد كلية التربية الرياضية / جامعة الموصل / جامعلة المبل كلية التربية الرياضية / جامعة الموصل / جامعة الموصل

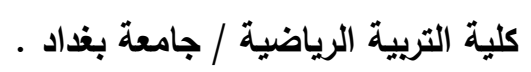
كلية التربية الرياضية / جامعة الموصل كلية التربية الرياضية / جامعة الموصل الرياضية / جامعة العصل

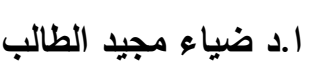

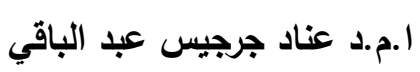

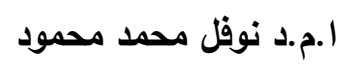
ا. ا.م.د محمد صالح محمد محمد محود د نبيل محمد عبد الله د موفق سعيد احمد " السادة الخبراء المتخصصون في مجال الاختبارات والمقاييس التبل كلية التربية الرياضية / جامعة بغداد .

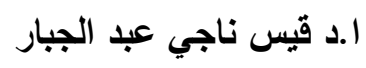

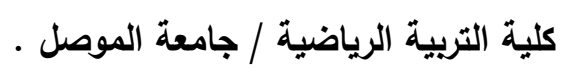

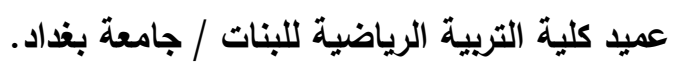

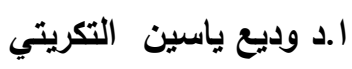

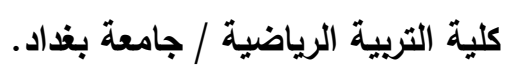

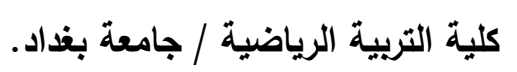

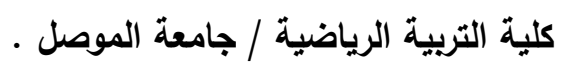
كلية التربية الرياضية / جامعة الموصل. كلية التربية الرياضية / جامعة الموصل .

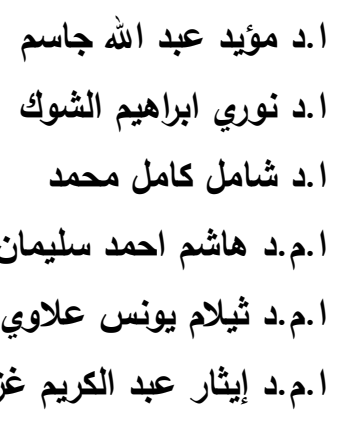


يبين الأوساط الحسابية والانحرافات المعيارية للمتغيرات المعتمدة في التكافؤ

\begin{tabular}{|c|c|c|c|c|c|c|c|}
\hline \multicolumn{2}{|c|}{ المجموعة الثالثة } & \multicolumn{2}{|c|}{ المجموعة الثانية } & \multicolumn{2}{|c|}{ المجموعة الأولى } & \multirow{2}{*}{ والقياس } & \multirow{2}{*}{ /المتفيرات الميع والمعاليم الإحصائية } \\
\hline$\varepsilon^{ \pm}$ & س & $\varepsilon \pm$ & س & $\varepsilon \pm$ & س & & \\
\hline . ‘Ar & iv,v. & $\cdot, \leqslant \wedge$ & IV,r. & . ، v^ & $I V, \Lambda$. & ( سنة ) & العمر \\
\hline$r, O r$ & $1 \pi \Lambda, r$. & $r, £ \wedge$ & $14 \wedge, \wedge$. & $r, v_{1}$ & $179,8$. & ( سم ) & الطول \\
\hline$r, \cdot r$ & ov,r. & $\varepsilon, \vee \wedge$ & ov, 4 . & $r, \leqslant \vee$ & $0 \wedge, 1$. & ( كغ ) & الوزن \\
\hline$\cdot, r^{9}$ & $r, v \vee$ & $\cdot, 11$ & $r, q \varepsilon$ & • & $r, \Lambda r$ & (ثانية) & السرعة الانتقالية القصوى \\
\hline Ir, rq & $r \cdot \Lambda, 0$. & $1 \%, 01$ & $r \cdot T, r$. & $1,0\}$ & $r \ldots, r$. & (سم ) & القوة الانفجارية للرجلين \\
\hline Y,YA & $r \wedge, q$. & $r, \infty 0$ & $r 9,10$ & r,Y & $\uparrow \Lambda, r$. & (متر) & القوة المميزة بالسرعة للرجلين \\
\hline , VA & $1 \leqslant, .4$ &., 04 & $1 \leqslant, \leqslant 9$ & $\cdot, 9$. & $1 \leq, 14$ & (ثانية) & الإنجاز في عدو ـ1 متر \\
\hline
\end{tabular}

وللتعرف على دلالة الفروق في المتغيرات المذكورة أنفا وللتأكد من تكافؤ المجاميع الثلاثة تم إجراء تحليل التباين بين هذه المجاميع كما هو مبين في الجدول رقم (r)

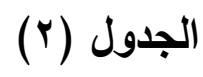

$1 \cdot 1$ 
تحليل التباين في المتغيرات المعتمدة في التكافؤ

\begin{tabular}{|c|c|c|c|c|c|c|}
\hline (ف) & (المحسوية & $\begin{array}{r}\text { (التباين) } \\
\text { متوسط المريعات }\end{array}$ & المربعات & الحرية & مصدر التباين & المتغيرات \\
\hline \multirow{21}{*}{ o } & $1, r v$ & $\cdot, v \cdots$ & $1, \varepsilon \ldots$ & r & بين المجموعات & \multirow{3}{*}{ العمر } \\
\hline & &., 011 & $1 \mu, \wedge \ldots$ & rv & داخل المجموعات & \\
\hline & & & $10, r \ldots$ & rq & المجموع الكلي & \\
\hline & •, Yq & $r, \uparrow \ldots$ & $\vee, r \ldots$ & r & بين المجموعات & \multirow{3}{*}{ الطول } \\
\hline & & Ir,r.V & $r r q, \uparrow .$. & TV & داخل المجموعات & \\
\hline & & & rrq,A.. & rq & المجموع الكلي & \\
\hline & $\cdot, 11$ & 1, 1, & T,Y & $r$ & بين المجموعات & \multirow{3}{*}{ الوزن } \\
\hline & & $1 \leqslant, \vee \backslash \wedge$ & rqv, \&.. & YV & داخل المجموعات & \\
\hline & & & צ & rq & المجموع الكلي & \\
\hline & $1,1 r$ & $\cdot, \cdot \uparrow \wedge$ & $\cdot, 1 r v$ & r & بين المجموعات & \multirow{3}{*}{ الانتقاليـــــــــــة } \\
\hline & & $\cdot, .71$ & $1,70 \mathrm{~V}$ & rV & داخل المجموعات & \\
\hline & & & $1, \vee 9 \varepsilon$ & rq & المجموع الكلي & \\
\hline & $r, r q$ & \& & $\Lambda \leqslant T, Y 44$ & $r$ & بين المجموعات & \multirow{3}{*}{ المجلين الانفجارية } \\
\hline & & $\mid \vee \wedge, \varepsilon \leqslant \wedge$ & $\varepsilon \wedge \backslash \wedge, 1 \ldots$ & $r v$ & داخل المجموعات & \\
\hline & & & צדיז,וד4 & rq & المجموع الكلي & \\
\hline & $\cdot, \wedge \wedge$ & $\varepsilon, q \mu r$ & $9, \wedge 44$ & r & بين المجموعات & \multirow{3}{*}{ القـــــ المميـزة للرجلين } \\
\hline & & 0,71 & $101,7 \ldots$ & rv & داخل المجموعات & \\
\hline & & & 171,874 & rq & المجموع الكلي & \\
\hline & $\cdot, \wedge r$ & $\cdot, \leqslant 9$. & $\cdot, 9 \wedge$. & r & بين المجموعات & \multirow{3}{*}{ ل. الإنجاز في عتر } \\
\hline & & $\cdot, 0 \wedge 9$ & $10,9, \varepsilon$ & $r v$ & داخل المجموعات & \\
\hline & & & $17, \wedge \wedge \varepsilon$ & rq & المجموع الكلي & \\
\hline
\end{tabular}

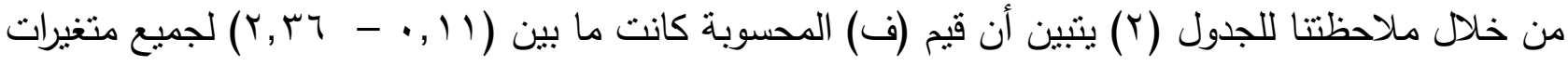

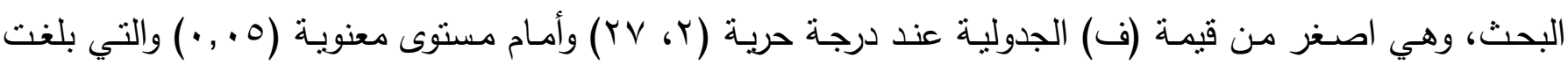


( r, ro ) مما يدل على عدم وجود فروق ذات دلالة معنوية بين مجاميع البحث التجريبية في المتغيرات المعتمدة في التكافؤ، وهو يدل على تكافؤ هذه المجاميع. r- الأجهزة والأدوات المستخدمة:

جهاز لقياس درجة انحدار" الأرض (Theodolite). دراجة بخارية نم استخدامها في تدريبات السرعة بالمساعدة.

جهاز قياس الطول إلكتروني نوع (OSK).

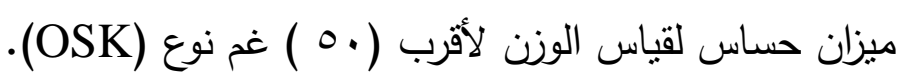
إطارات سيارة" عدد ( 7 ).

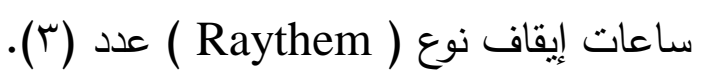
شريط قياس بطول (•0) منراً. شواخص عدد ( 1 ). حبال .

\section{r-ه تحديد القياسات والاختبارات المستخدمة:}

ـ القياسات الجسمية: ( قياس الطول ، وقياس الوزن)

- الاختبارات البدنية: وشملت:اختبار عدو • م مترا من بداية متحركة (لقياس السرعة الانتقالية القصوى)، واختبار

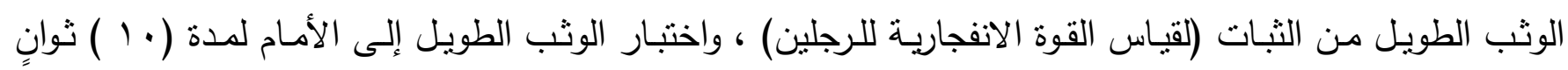

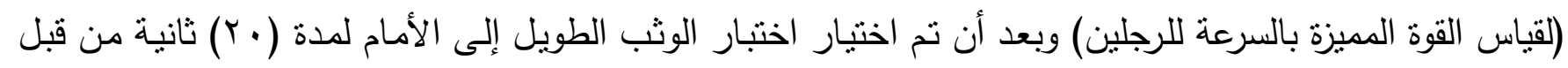

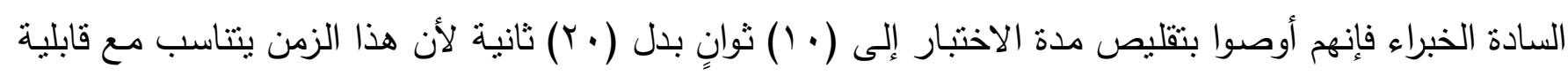

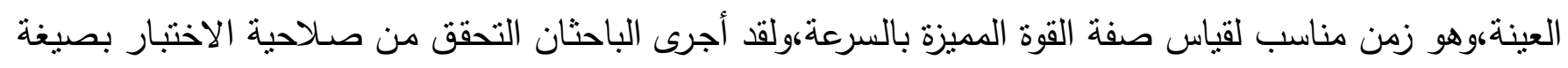

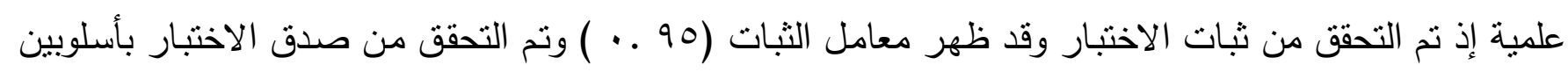
وهما الصدق الذاتي وكان معامل الصدق (Y9 , · ) ) وصدق المحكات للمجموعات المنضادة.

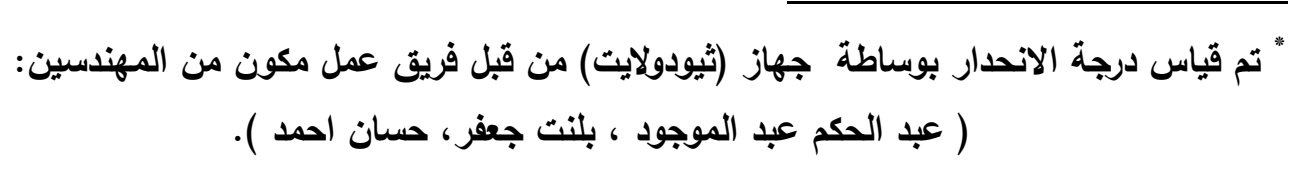

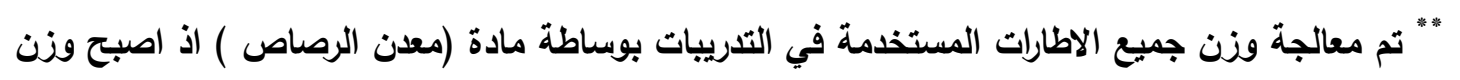

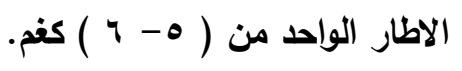


- اختبار عدو . . 1 متر : تم اعتماد القانون الدولي بألعاب القوى في تتفيذ هذا الاختبار،إذ ينطلق

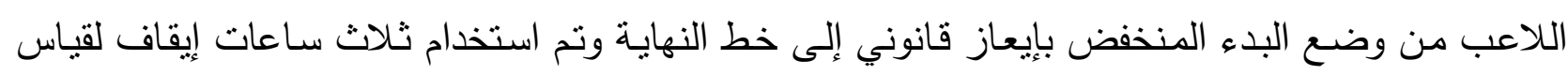

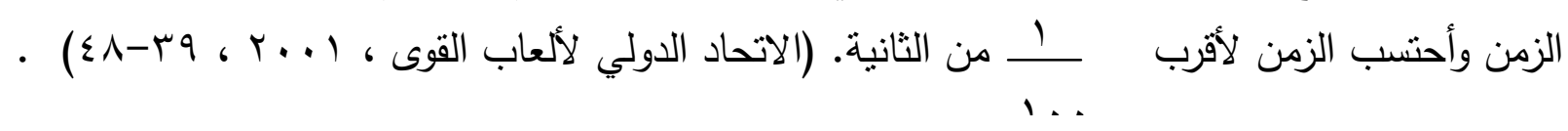

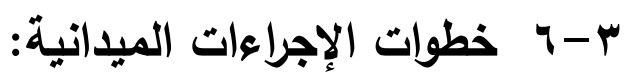

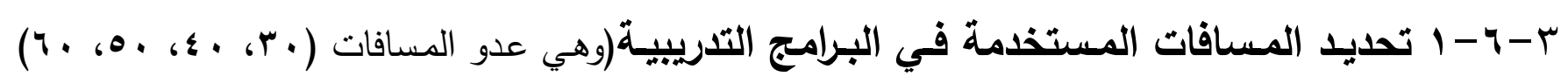
متراً، بعد تحليل محتوى المصادر العلمية.

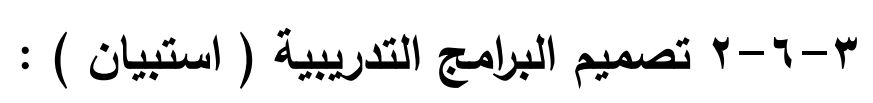

تم تصميم ثلاثة برامج تدريبية مقترحة خاصة بتدريبات السرعة بالمساعدة والمقاومة (الملحق(؟)) وتم عرضها على

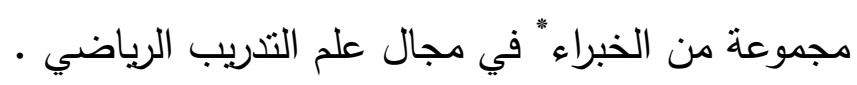

r- r-r اختبار عينة البحث في المسافات المحددة بالبرامج التدريبية: قبل البدء بتنفيذ إجراءات البحث تم اختبار عينه البحث في المسافات المحددة في البرامج التنريبية باستخدام أسلوبي المساعدة والمقاومة للتعرف على زمن الإنجاز الأقصى لهذه المسافات.

* السادة الخبراء في مجال علم الترريب الرياضي الذين تم عرض البرامج التدريبية المقترحة عليهم: كلية التربية الرياضية /جامعة بذاد . أ.د احمد سعيد احمد كلية التربية الرياضية /جامعة بغداد.

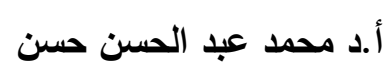

كلية التربية الرياضية /جامعة الموصل .

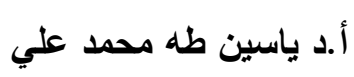

كلية التربية الرياضية /جامعة الموصل . أ. أد ضياء مجيد الطالب بالبين طهدي

كلية التربية الرياضية /جامعة الموصل . أ.م.د عناد جرجيس عبد الباقي

كلية التربية الرياضية /جامعة الموصل . أ.م.د نوفل محمد محمود كلية التربية الرياضية /جامعة بذاد . كلية التربية الرياضية /جامعة الموصل. أ.م.د محمد صالح محمد كلية التربية الرياضية /جامعة الموصل. د. نبيل محمد عبد الله د. موفق سعيد احمد 
أجرى الباحثان مع فريق العمل" تجربة استطلاعية على (0) طلاب من مجتمع البحث والذين تم استبعادهم عند تتفيذ

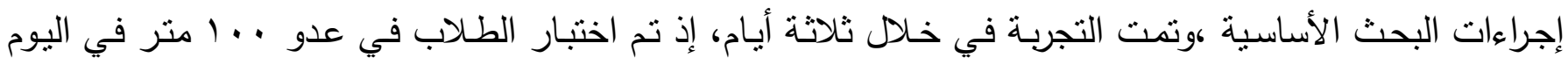

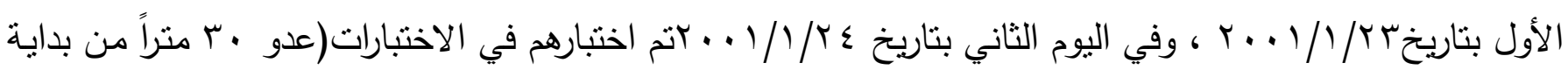

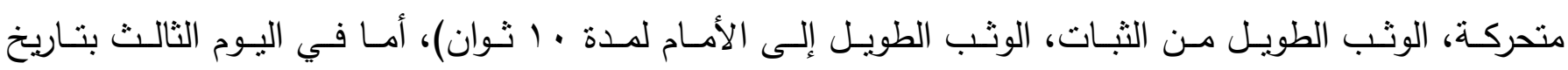

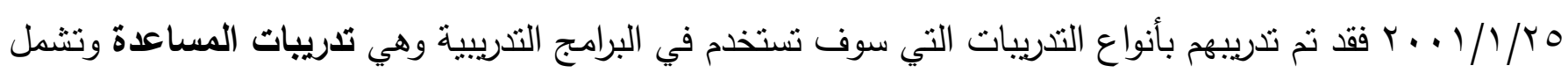

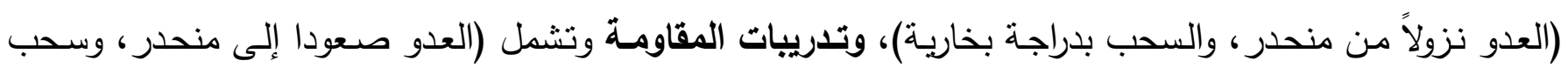

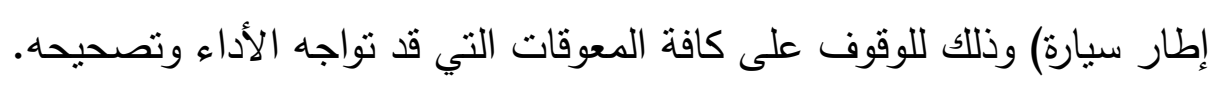

ץ- - -ه مواصفات التدريبات المستخدمة في البرامج التدريبية:

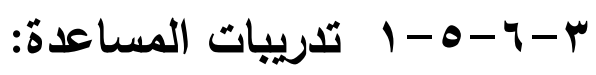
- العدو نزولا من منحدر (Down Hill): وهو عبارة عن العدو السريع فوق منحدر كانت درجة انحداره (0, ( )

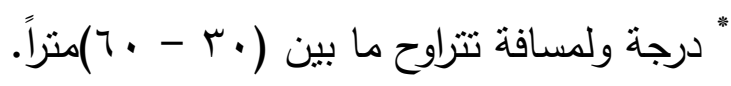

-طريقة السحب (Towing): استخدم الباحثان دراجة بخارية لسحب اللاعب ،إذ نم تتبيت قضيب حديدي يبعد مترا واحدا عن نهاية الدراجة وتم تصميمه ليكون بمستوى صدر الرياضي .

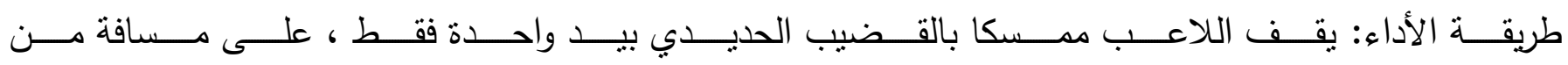

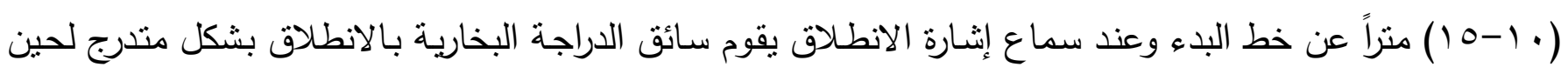

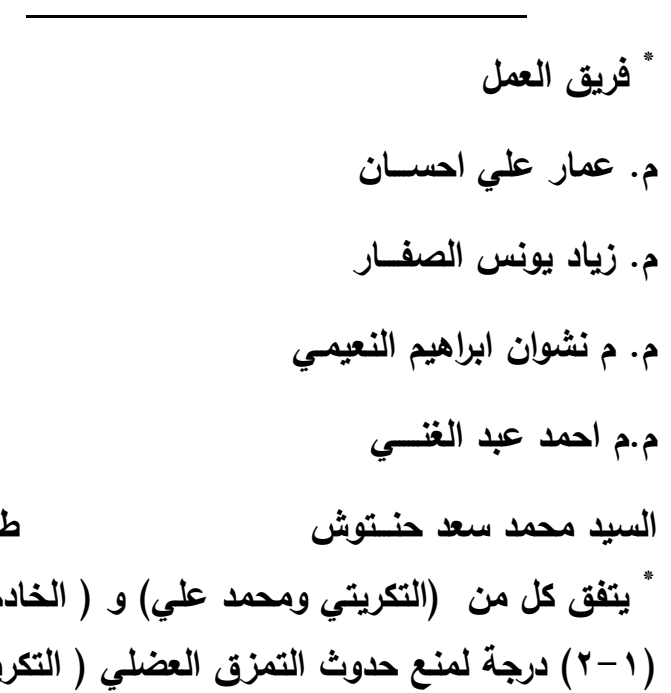




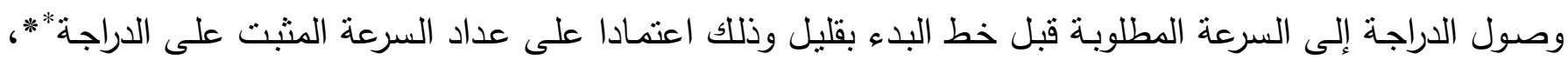

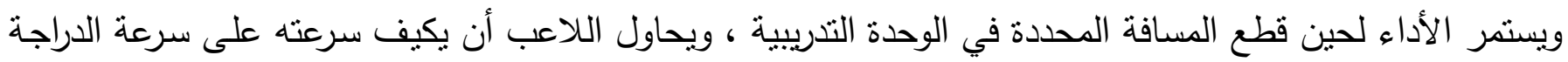

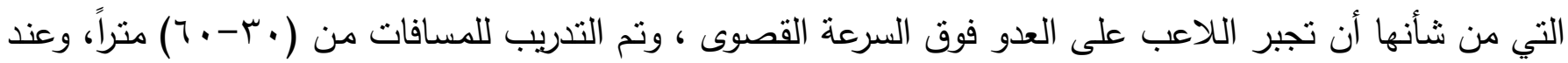
قطع المسافة المطلوبة للأداء يقوم اللاعب بترك قضيب الدراجة البخارية ، وقد نم استخدام ساعة إيقاف للتأكد من شدة

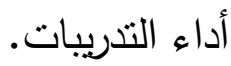

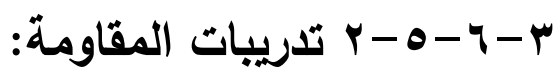

-العدو صعودا على منحدر (Up Hill): أي العدو السريع على منحدر كانت درجة التدرج الصاعد فيه (, (1)"

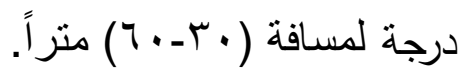

\section{- العدو السريع بسحب الأداة (سحب إطار سيارة) (Harness Training):}

طريقة الأداء : يسحب اللاعب إطار سيارة مربوطاً بحبل مثبت في حزام حول خصر اللاعب وبالثدة الخاصة بكل

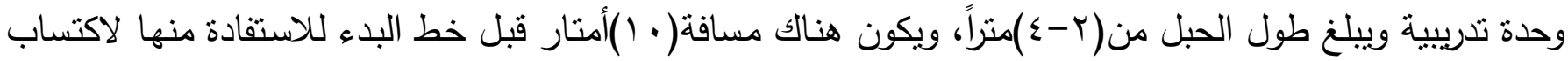

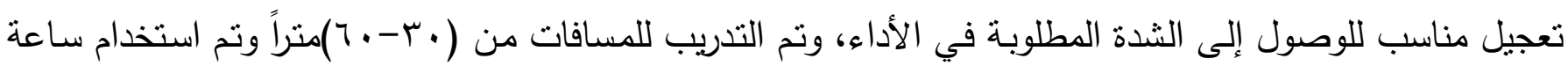

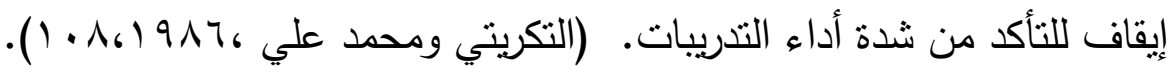

\section{ץ- - - - الاختبارات القياسات القبلية:}

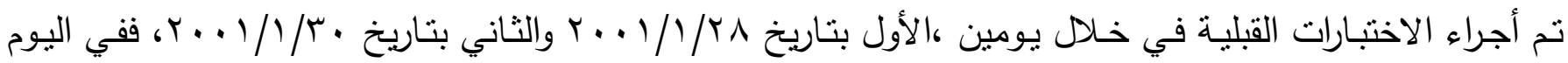

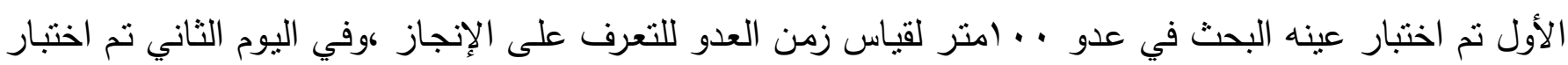

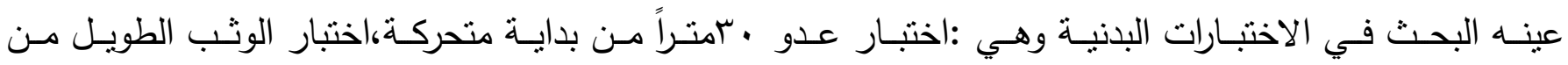
الثبات،اختبار الوثب الطويل إلى الأمام لمدة (• (1) ثوانٍ. rتم البدء بتطبيق البرامج التدرييية لمجاميع البحث، إذ تم وضع هذه البرامج بعد الإطلاع على مبادئ علم التدريب

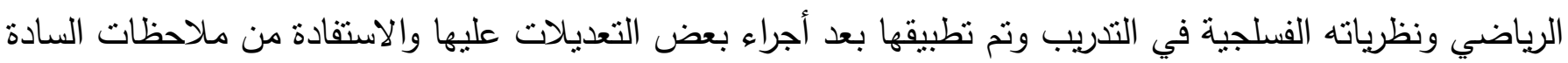
الخبراء في مجال علم التدريب الرياضي ، تم تتفيذ البرامج الخاصة بتدريبات السرعة بالمساعدة والمقاومة على عينه

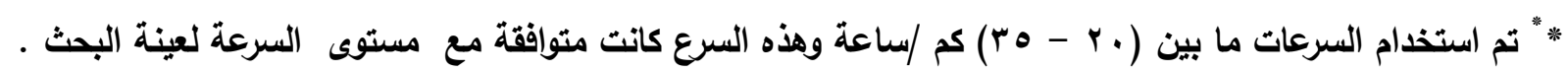

"ينصح (التكريتي ومحمد علي) ان لا تزيد درجة التدرج الصاعد عن (؛) درجات وذلك لتجنب التعب والتثنج العضلي. (التكريتي 
البحث وبواقع وحدتين تدريبيتين في كل أسبوع" ولمدة(r ( ) أسبوعا وقسمت إلى أربعة دورات متوسطة وبموجات

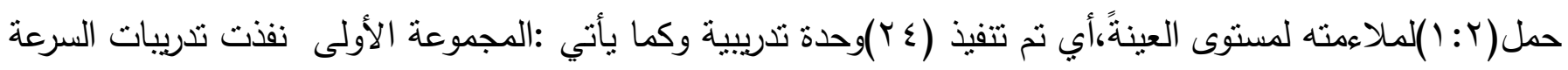

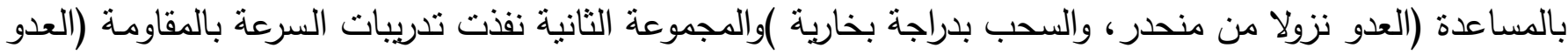

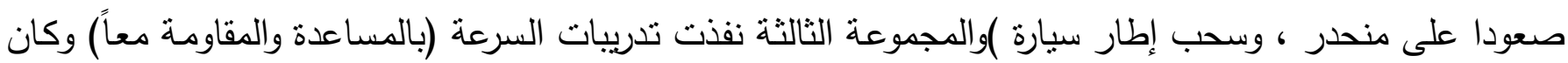

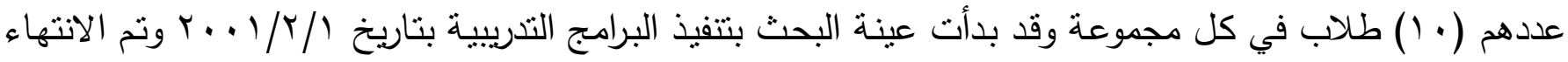

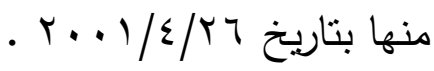

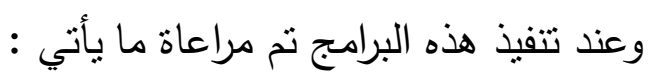
- تم اختبار عينة البحث في المسافات المحددة في البرامج التنريبية لكل نوع من تدريبات السرعة المستخدمة للتعرف على زمن الإنجاز الأقصى (الثدة القصوى) لهذه المسافات. - تم العدو في كافة التدريبات المستخدمة في البرامج التدريبية من خلال البدء الطائر.

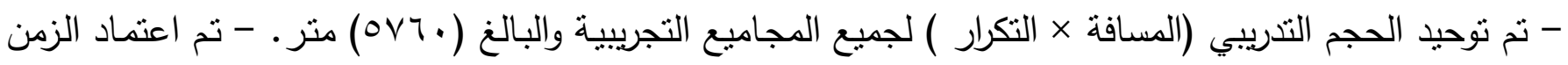

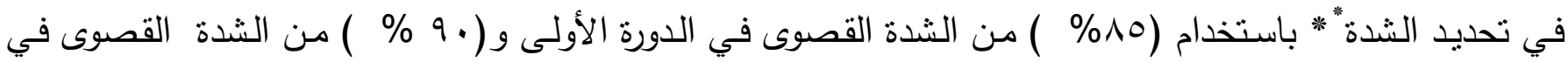

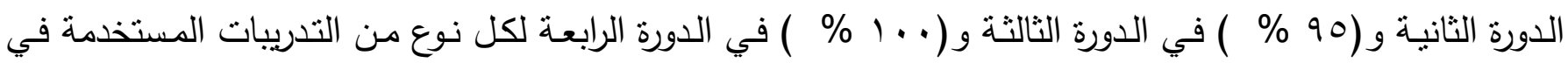

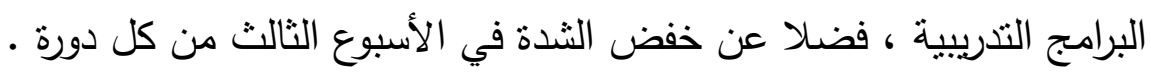
- نفذت المجموعة الثالثة تدريبها في كل دورة باستخدام أسلوب المساعدة في الأسبوع الأول والمقاومة في الأسبوع

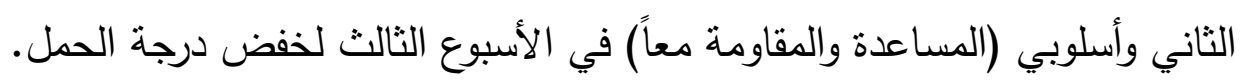
ب-1 - الاختبارات والقياسات البعدية :

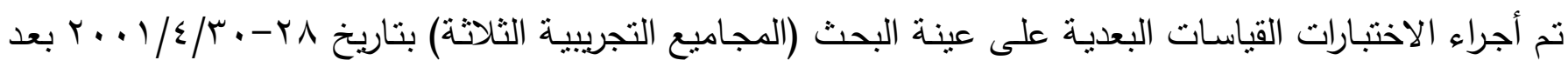
الانتهاء من تتفيذ البرامج التدريبية وبنفس الأسلوب والتسلسل الذي أجريت بهما الاختبارات القياسات القبلية .

*بالنسبة الى فئسة الشباب تعطى (ץ-ץ)وحدات تدريبية في الاسبوع ولفترة زمنية يجب ان لا تقل عن شهرين لاجل احداث اثر

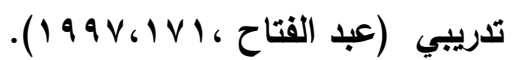

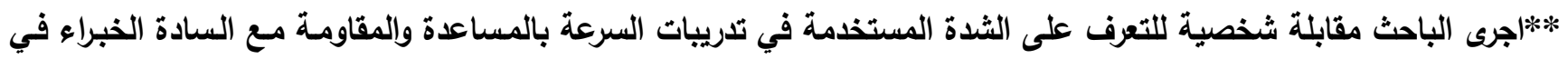

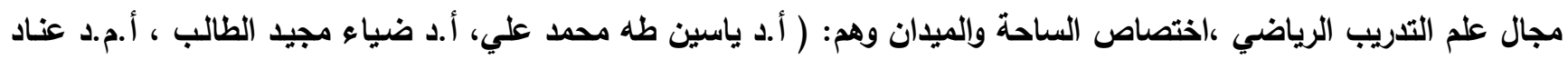

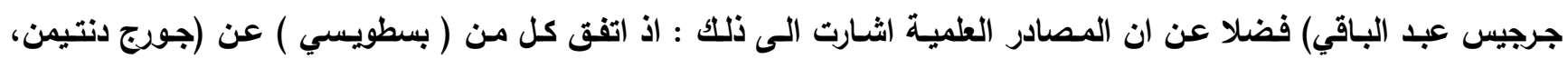

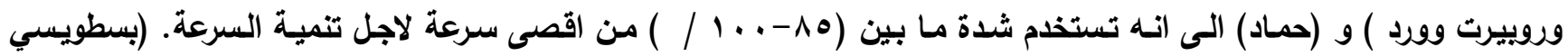

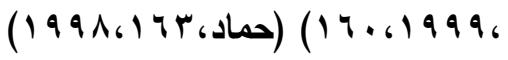


- ولضمان تعرض جميع أفراد العينـة لنفس المدة الزمنية بين الإحماء والبدء بالاختبارات تم ترتيب عملية الإحماء

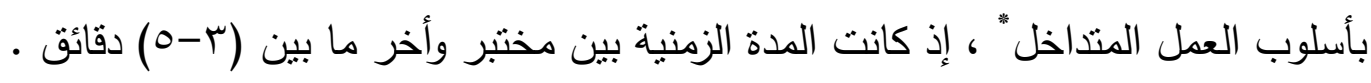
r- الوسائل الإحصائية:

$$
\begin{aligned}
& \text { - الوسط الحسابي. }
\end{aligned}
$$

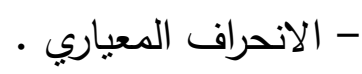

$$
\begin{aligned}
& \text { - تحليل التباين باتجاه واحد . } \\
& \text { - معامل الارتباط البسيط (بيرسون). }
\end{aligned}
$$

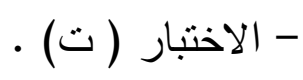

$$
\begin{aligned}
& \text { - اختبار دنكن متعدد المدى . }
\end{aligned}
$$

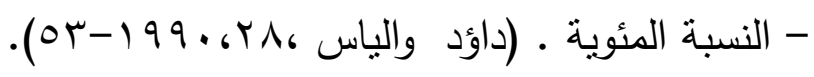

\section{1 - 1 - عرض ومناقشة النتائج}

ع - ا عرض وتحليل النتائج للإنجاز في عدو . . . متر ومناقشتها:

(r) الجدول

دلالة الفروق في إنجاز عدو .. 1 متر بين متوسطي الاختبارين (القبلي والبعدي)والمجاميع التجريبية والتداخل

\begin{tabular}{|c|c|c|c|}
\hline متوسط المجاميع & الاختبار البعدي & الاختبار القبلي & 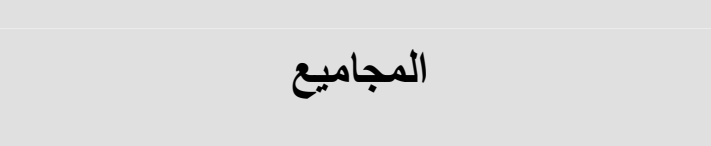 \\
\hline 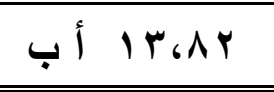 & 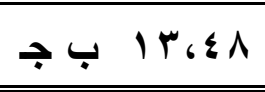 & 1 & المجموعة الأولى(أسلوب المساعدة) \\
\hline I I \&, ro & 1 ع ، 1 أب & $1 \leq \leqslant \leq 9$ & المجموعة الثانية(أسلوب المقاومـة) \\
\hline \multirow[t]{2}{*}{ 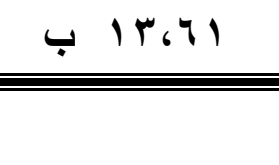 } & ج14.17 & ل & المجموعة الثالثة(أسلويا المساعدة والمقاومة) \\
\hline & n & I I \& r & متوسط الاختبارين (ثانية) \\
\hline
\end{tabular}

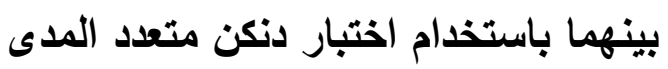

* العمل المتداخل : اي وجود فترة زمنية بين المختبر الاول والثاني وبين المختبر الثاني والثالث وبين الثالث والثرابع

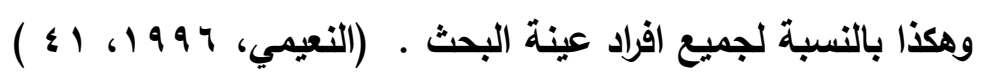




\section{يتبين من الجدول(r)ما يأني:}

-وجود فروق ذات دلالة معنوية" في إنجاز عدو . . متر بين منوسطي الاختبارين القبلي والبعدي ولصالح الاختبار البعدي.

- وجود فروق ذات دلالة معنوية في إنجاز عدو . ـ مثر بين منوسطات المجاميع ولصالح المجموعة الثالثة

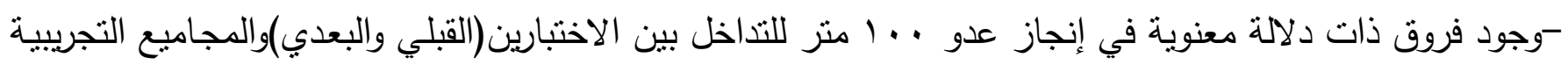
ولصالح المجموعة الثالثة.

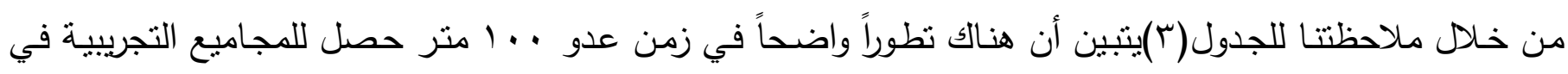
الاختبار البعدي مقارنةً بالاختبار القبلي والذي ارتقى إلى مستوى المعنوية،ويمكن للباحثان أن يعزوا هذه النتيجة إلى فاعلية

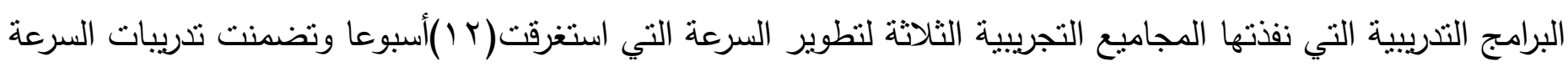

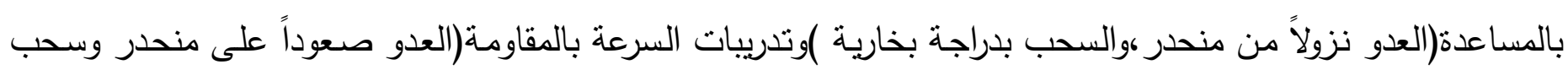

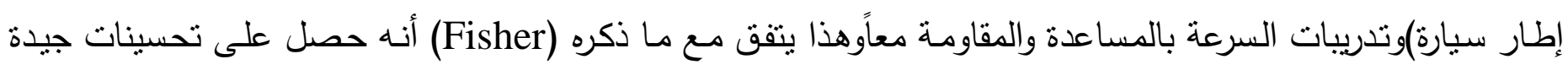

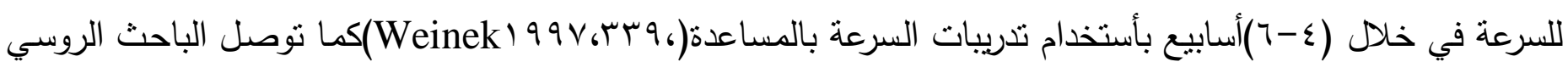

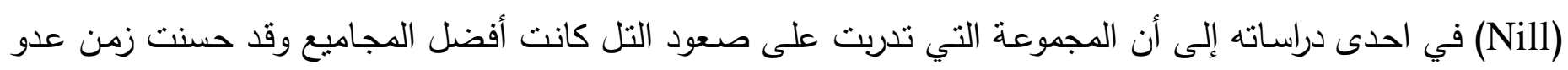

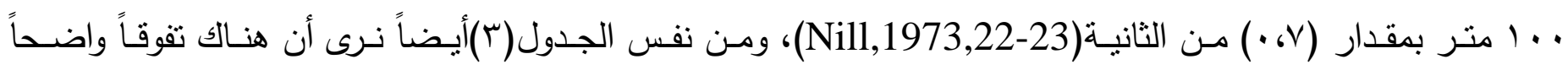

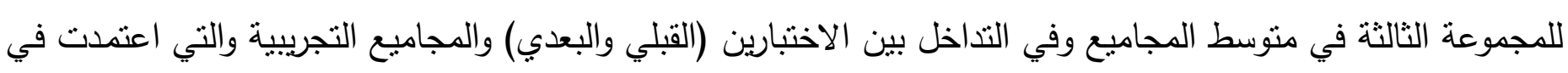

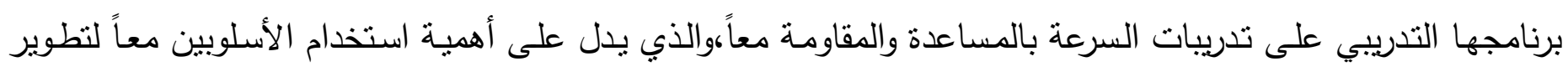

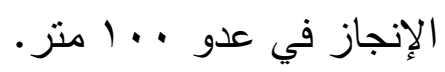

ويمكن للباحثان إعزاء تفوق المجموعة الثالثة إلى أن هناك تطوراً حصل بالتأكيد لدى هذه المجموعة في طول الخطوة

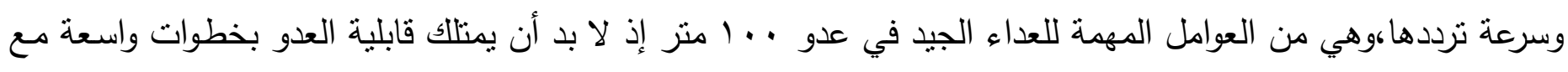

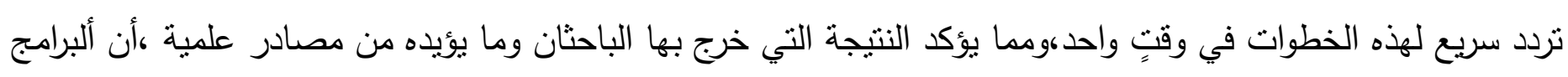

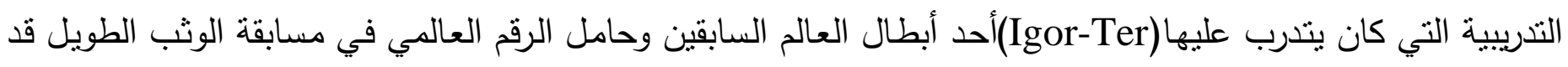

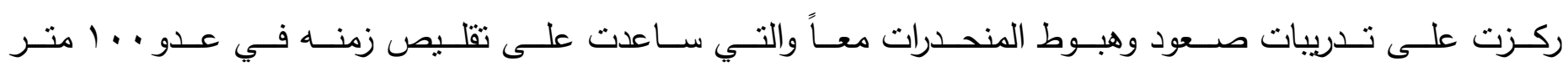

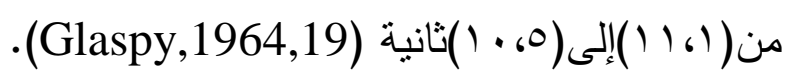

ان الأوساط الحسابية المتعلقة بالإنجاز في عدو . . 1 متر وزمن اختبار عدو • امتراً ذات الاحرف

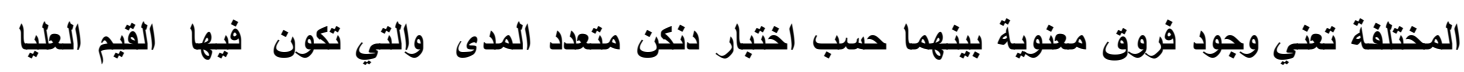
هي التي تأخذ الحرف (أ) ويليها الحرف (ب) و هكذا بحسب الحروف الأبجدية وتكون القيم المعنوية هنا

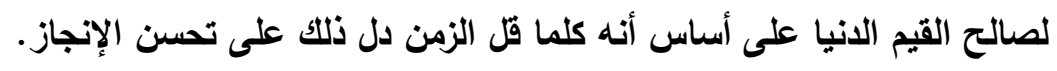


צ - r عرض وتحليل نتائج الصفات البدنية ومناقشتها:

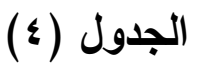

يبين دلالة الفروق في إنجاز عدو • ب متر بين متوسطي الاختبارين (القبلي

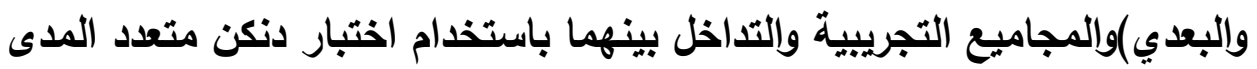

\begin{tabular}{|c|c|c|c|}
\hline متوسط المجاميع & الاختبار البعدي & الاختبار القبلي & 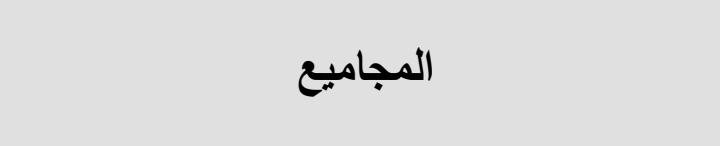 \\
\hline 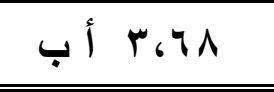 & ج & 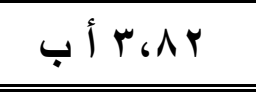 & المجموعة الأولى(أسلوب المساعدة) \\
\hline I r.Ar & r. & I r.q & المجموعة الثانية(أسلوب المقاومة) \\
\hline \multirow[t]{2}{*}{ 年 ب.04 } & O Or.r & 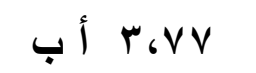 & المجموعة الثالثة(أسلويا المساعدة والمقاومة) \\
\hline & r ror ror & أ $r_{6} \wedge \varepsilon$ & متوسط الاختبارين (ثانية) \\
\hline
\end{tabular}

يتبين من الجدول(§)ما يأتي:

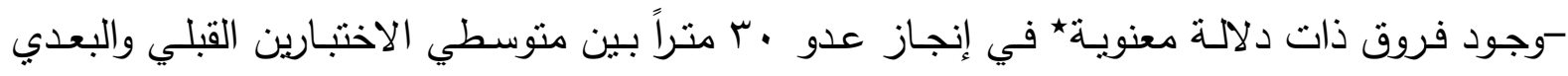
ولصالح الاختبار البعدي.

- وجود فروق ذات دلالة معنوية في إنجاز عدو ـr متراً بين منوسطات المجاميع ولصالح المجموعة الثالثة.

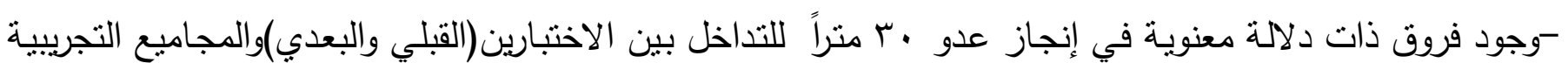
ولصالح المجموعة الثالثة.

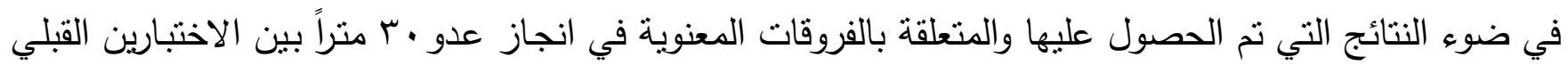

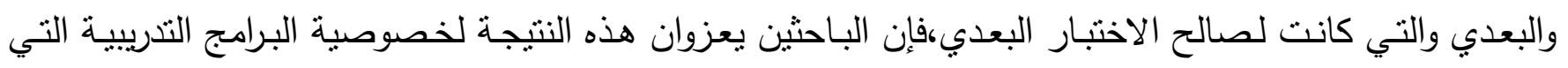

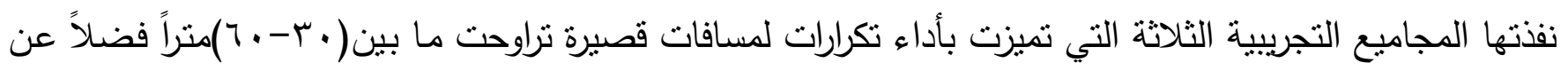

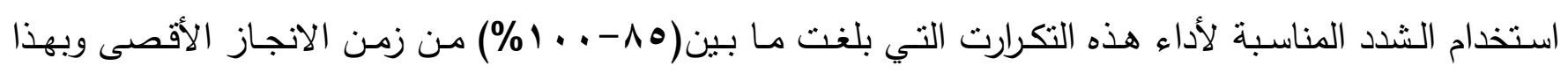

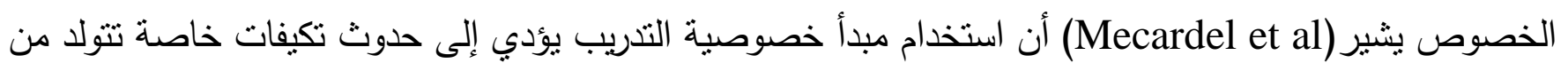

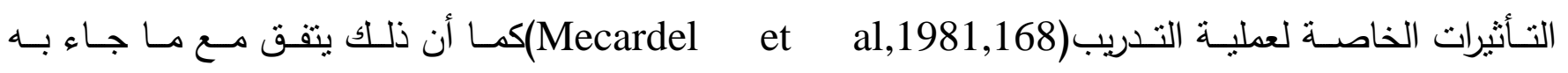

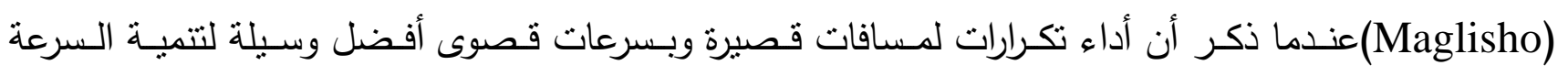
.(Maglisho,1982,309) أما بالنسبة للفرق المعنوي في متوسطات المجاميع وفي التداخل بين الاختبارين (القبلي والبعدي)وفي المجاميع

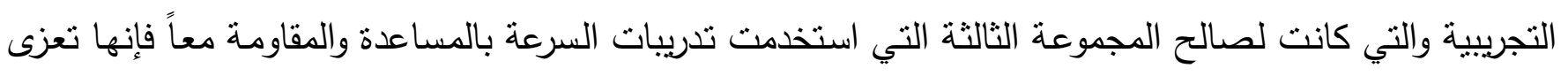
إلى التفوق الحاصل للمجموعة المذكورة في زمن عدو ·. (مثر بعد الجمع ما بين تدريبات المساعدة والمقاومة والتي

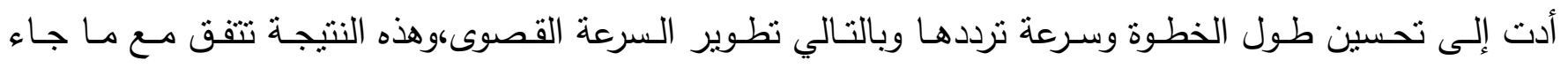


(Ozoline et el) el el

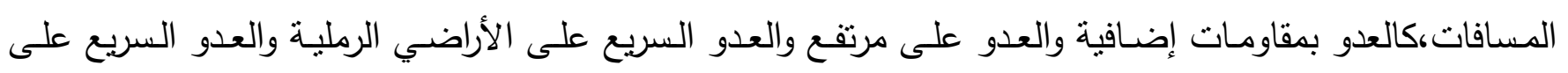
منحدر والعدو على الثريط الدوار وتمرينات السحب بوساطة مركبة"(Ozoline et el,1983,164-166).

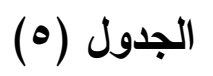

يبين دلالة الفروق في إنجاز الوثب الطويل من الثبات بين متوسطي الاختبارين (القبلي

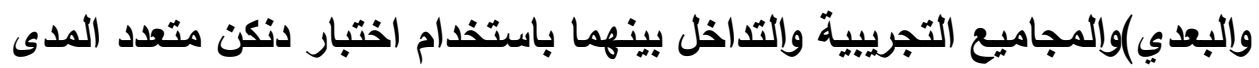

\begin{tabular}{|c|c|c|c|}
\hline $\begin{array}{c}\text { متوسط المجاميع } \\
\text { (سم) }\end{array}$ & الاختبار البعدي & الاختبار القبلي & 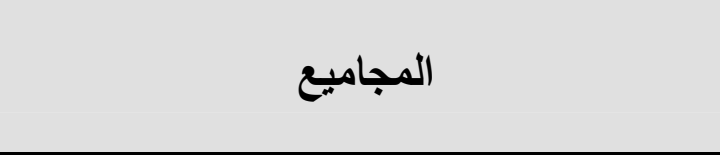 \\
\hline 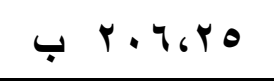 & 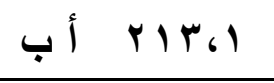 & 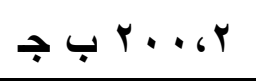 & المجموعة الأولى(أسلوب المساعدة) \\
\hline 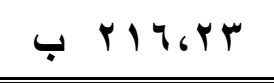 & 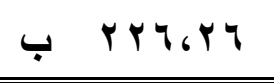 & $د r \cdot Y, r$ & المجموعة الثانية(أسلوب المقاومة) \\
\hline \multirow[t]{2}{*}{ I rratr. } & I rrrov. & $د r \cdot \Lambda_{6} 0$ & المجموعة الثالثة(أسلويا المساعدة والمقاومة) \\
\hline & I Y Y \&. . r & ب r.\&،97 & متوسط الاختبارين (سم) \\
\hline
\end{tabular}

$$
\text { يتبين من الجدول(0)ما يأتي: }
$$

-وجود فروق معنويةضفي إنجاز الوثب الطويل من الثبات بين منوسطي الاختبارين ولصالح الاختبار البعدي. - وجود فروق معنوية في إنجاز الوثب الطويل من الثبات بين متوسطات المجاميع ولصالح المجموعة الثالثة. -وجود فروق معنوية في إنجاز الوثب الطويل من الثبات للتناخل بين الاختبارين(القبلي والبعدي)والهجاميع لونيع التجريبية ولصالح المجموعة الثالثة.

(7) ( الجدول) 
يبين دلالة الفروق في إنجاز الوثب الطويل إلى الأمام لمدة( • 1) ثوان بين متوسطي

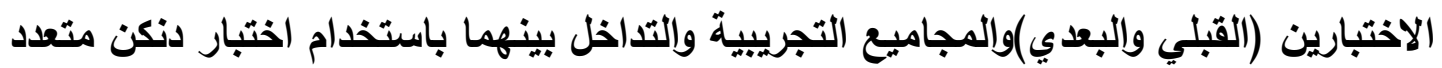

المدى

\begin{tabular}{|c|c|c|c|}
\hline متوسط المجاميع & الاختبار البعدي & الاختبار القبلي & 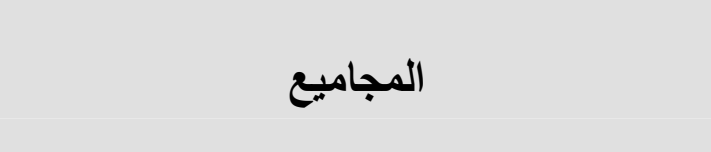 \\
\hline i r $\wedge_{6}, \Delta V$ & 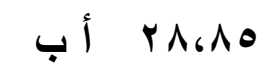 & 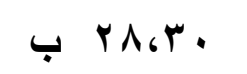 & المجموعة الأولى(أسلوب المساعدة) \\
\hline I rq.Ar & 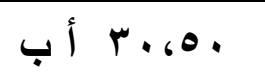 & أ & المجموعة الثانية(أسلوب المقاومة) \\
\hline \multirow[t]{2}{*}{ ir. r. } & D & r r & المجموعة الثالثة(أسلويا المساعدة والمقاومة) \\
\hline & rr. r r & ب r^، & متوسط الاختبارين (متر) \\
\hline
\end{tabular}

يتبين من الجدول(T) ما يأتي:

-وجود فروق معنوية في إنجاز الوثب الطويل إلى الأمام لمدة( • () ثوان بين منوسطي الاختبارين القبلي والبعدي ولصالح الاختبار البعدي.

- وجود فروق معنوية في إنجاز الوثب الطويل إلى الأمام لمدة( • ( ) ثوان بين متوسطات المجاميع ولصالح المجموعة الثالثة.

-وجود فروق ذات دلالة معنوية في إنجاز الوثب الطويل إلى الأمام لمدة(• () ثوان للتداخل بين الاختبارين (القبلي والبعدي)والمجاميع التجريبية ولصالح المجموعة الثالثة.

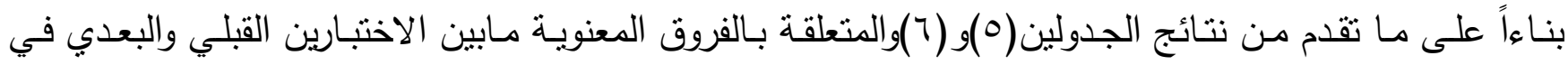

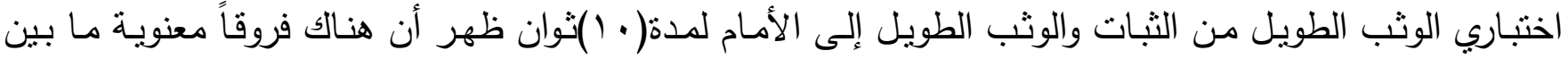
الاختبارين القبلي والبعدي لمجاميع البحث ولصالح الاختبار البعدي والذي يدل على تطور الصفتين المذكورتين بعد الهد تتفيذ البرامج التندريبية.

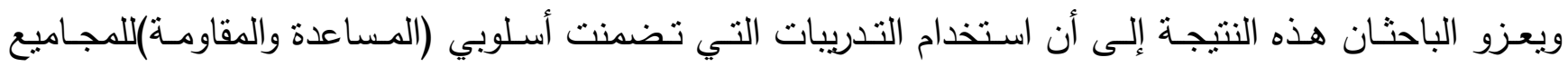
التجريبية الثلاثة أدت إلى زيادة قوة عضلات الرجلين وبالتالي أحدثت تطوراً في صفتي القوة الانفجارية والقوة المميزة

* إن الأوساط الحسابية المتعلقة بالإنجاز في الوثب الطويل من الثبات والوثب الطويل لمدة ( • ()ثوان ذات الأحرف المختلفة تغني وجود

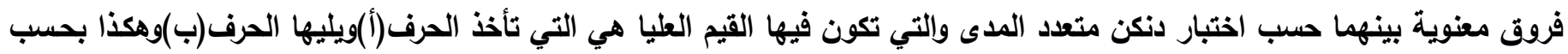

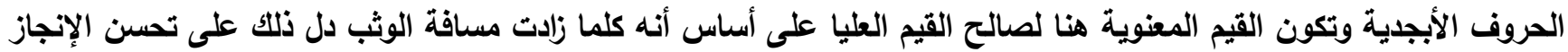


بالسرعة للرجلين لدى عينة البحث وهذا ما يتفق مع ما توصل إليه الباحثون (دينتيمن،ليترر ،سيفين،ميلاكوف،كوكس) بهذا الخصوص إلى أن استخدام التدريب على المرتفعات بطور قوة عضلات رجلي العداء ويزيد من طول الخطوة (التكريتي

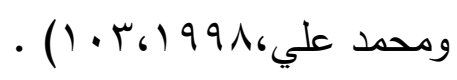

أما بالنسبة للفروق المعنويـة لصفة القوة الانفجاريـة للرجلين بين متوسط المجاميع التجريبية وفي التداخل بين

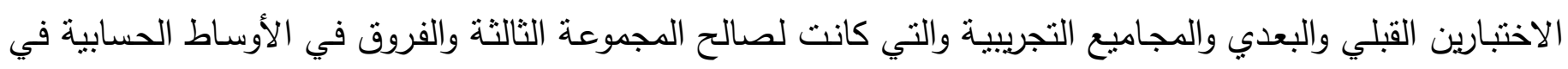

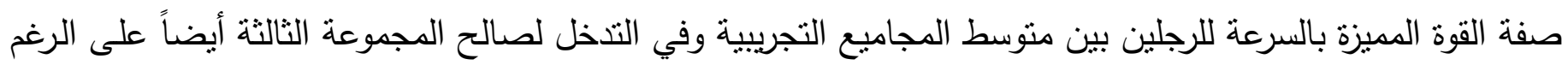

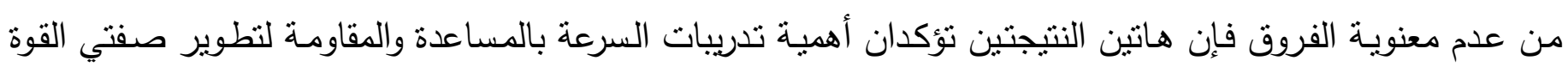

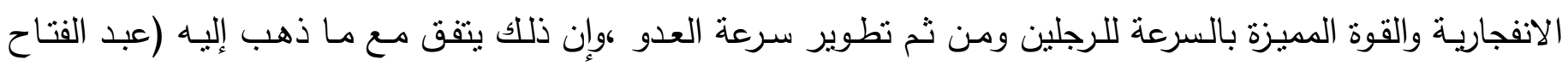

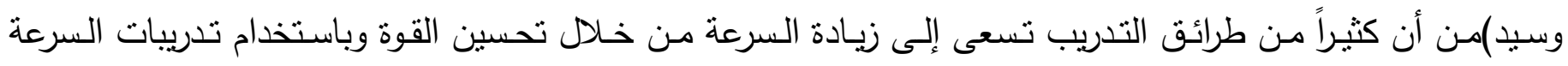

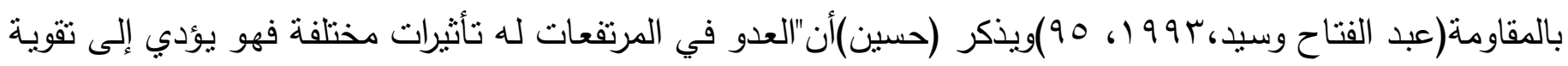

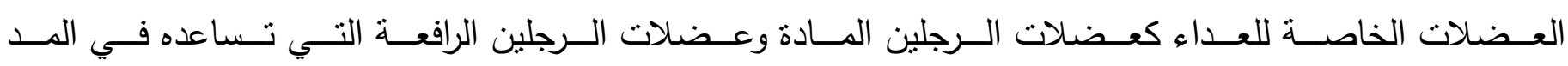

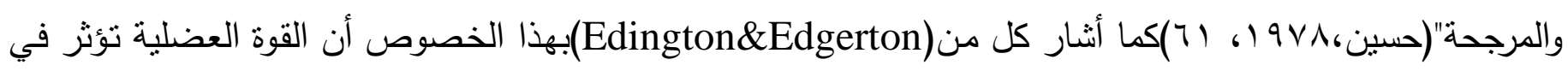
بصورة إيجابية في سرعة التقلص عندما تزداد المقاومة. (Edington\&Edgerton ,1976,64). ويرى الباحثان أن التحسن الذي حصل صفتي القوة الانفجارية والقوة الميزة بالسرعة للرجلين هو أحد أسباب التطور الذي الذي

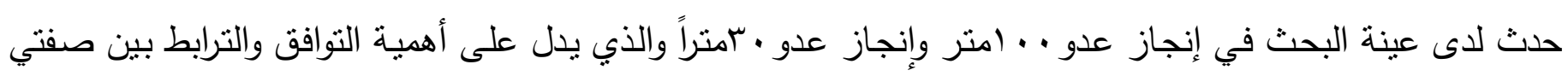
القوة والسرعة واللتين تعدان صفتين هامتين بالنسبة لعدائي المسافات القصيرة.

\section{0-الاستنتاجات والتوصيات ه- 1 الاستنتاجات:}

ا - أحدثت البرامج التدريبية التي نفتتها المجاميع التجريبية الثلاثة التي تضمنت ندريبات السرعة بالمساعدة والمقاومة تطوراً في الصفات البدنية (السرعة الانتقالية القصوى، والقوة الانفجارية للرجلين، والقوة المميزة بالسرعة للرجلين) فضلاً عن الإنجاز في عدو ...1 متر في الاختبار البعدي مقارنة بالاختبار القبلي. ץ- أحدث البرنامج التدريبي الذي نفذته المجموعة التجريبية الثالثة الذي تضمن تدريبات السرعة بالمساعدة والمقاومة معاً

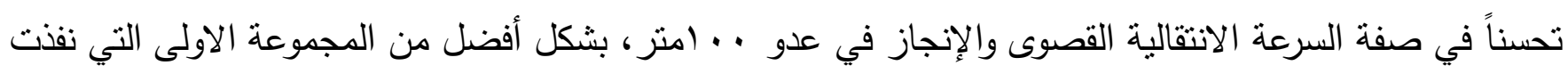
تدريبات السرعة بالمساعدة والمجموعة الثانية التي نفذت تدريبات السرعة بالمقاومة. 
ب- أحدث البرنامج التدريبي الذي نفذته المجموعة التجريبية الثالثة الذي تضمن تدريبات السرعة بالمساعدة والمقاومة معاً في الاختبار البعدي تفوقاً في صفة القوة الانفجارية للرجلين، وجاءت بالمرتبة الثانية المجموعة الثانية التي تضمنت تدريباتها السرعة بالمقاومة في حين حلت المجموعة الأولى التي تضمن برنامجها التدريبي السرعة بالمساعدة بالمرتبة الثالثة.

ع-أحدثت البرامج التدريبية التي نفذتها المجاميع التجريبية الثلاثة التي تضمنت تدريبات السرعة بالمساعدة والمقاومـة

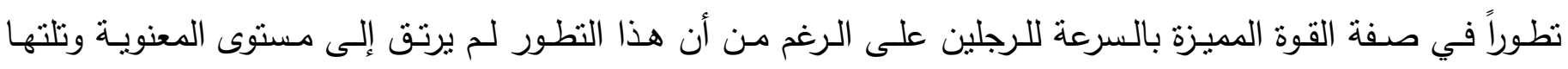

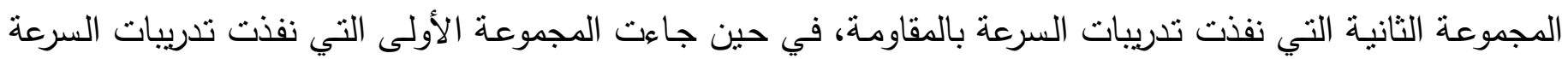
بالمساعدة بالمرتبة الثالثة. •-r التوصيات:

1- التأكيد على مدربي ألعاب القوى باستخدام تدريبات السرعة بالمساعدة والمقاومة معاً في الوحدات التدريبية الأسبوعية الخاصة بعدو المسافات القصيرة وبخاصة في عدو مسافة .. . (متر لأهميتها في تحسين الإنجاز .

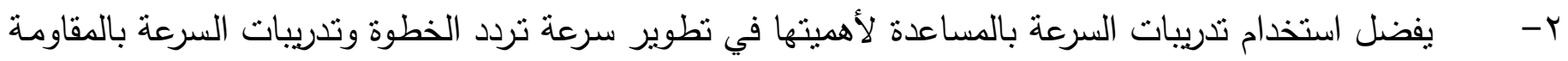

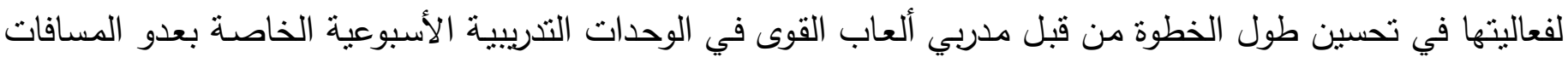
القصيرة وبخاصة عدو . (متر .

ب-ميكن استخدام تدريبات السرعة بالمساعدة والمقاومـة من قبل مدربي ألعاب القوى لتتمية وتطوير الصفات البدنيـة (السرعة الانتقاليـة القصوى، والقوة الانفجاريـة للرجلين، والقوة المميزة بالسرعة للرجلين) فضلاً عن استخدام تدريبات المقاومة لتحسين صفة القوة العضلية التي تعد العامل المؤثر في تطوير سرعة العدو. ع--إجراء دراسات مشابهة على فعاليات العدو السريع الأخرى وعلى لاعبين متقدمين ولكلا الجنسين في عدو المسافات القصبرة للوقوف على أثر هذه التدريبات.

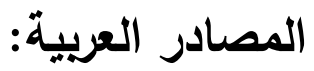

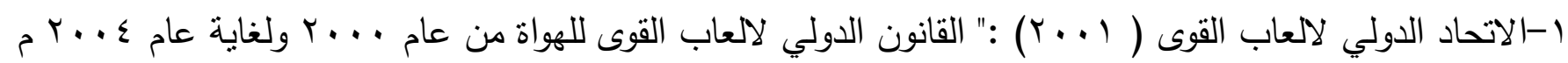

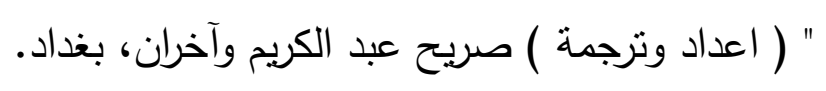
r-البساطي،أمر الله(99191):"قواعد واسس التّريب الرياضي وتطبيقاته"،مسلة المعارف ، الاسكندرية . 
" ب-بطويسي ، احمد بسطويسي (999 1) : " اسس ونظريات التدريب الرياضي " ، دار الفكر العربي ، القاهرة

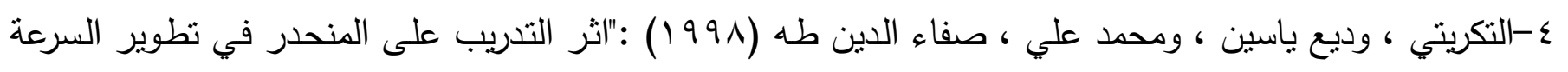

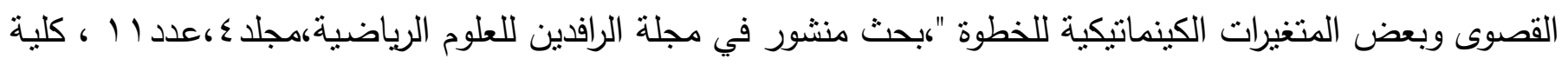
التربية الرياضية ، جامعة الموصل.

0-التكريتي،وديع ياسين،ومحمد علي،ياسين طه(T) 91 ():"الاعداد البدني للنساء"،دار الكتب للطباعة والنشر ،الموصل ד-حسانين محمد صبحي(990 1):"التقويم والقياس في التربية الرياضية"ج ( ،طس، دار الفكر العربي، القاهرة

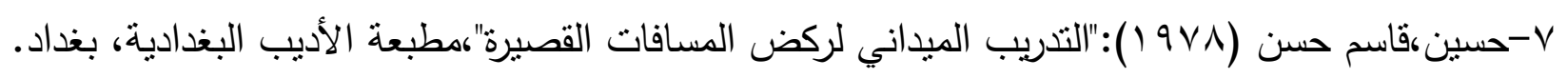
1-حماد،مفتي ابراهيم(9191 ():"التنريب الرياضي،تخطيط وتطبيق وقيادة "،ط (،دار الفكر العربي،القاهرة .

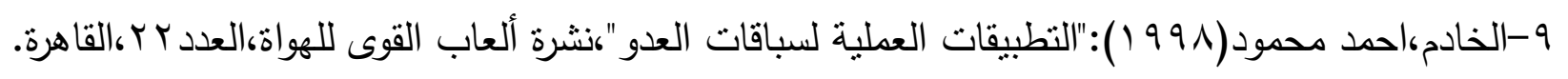
• 1-داؤد،خالد محمد،والياس،زكي عبد( •99 ())"الطرق الإحصائية للأبحاث الزراعية"،هطابع التعليم العالي، الموصل

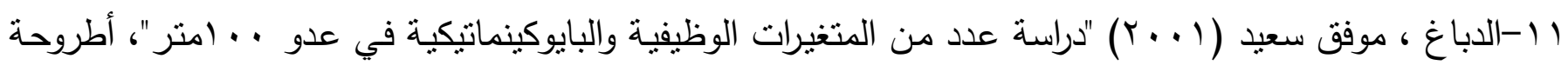
دكتوراه غير منشورة، كلية التربية الرياضية، جامعة الموصل.

r ا-عبد اللهأياد محمد( . . ب):"اثر استخدام اساليب مختلفة من التدريب الفتري على عدد من المتغيرات الوظيفية

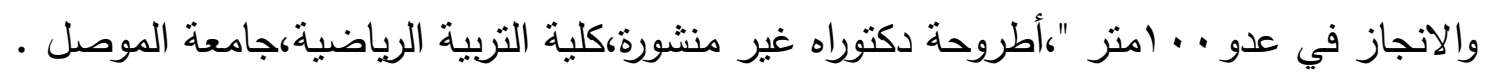

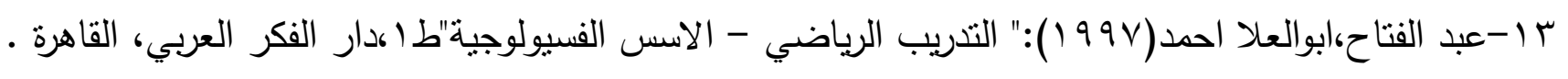
ع اعبد الفتاح،ابو العلا أحمد،وسيد،احمد نصر الدين(س99 (1) :"فسيولوجية اللياقة البدنية"،ط (،دار الفكر العربي القاهرة. 10-عثمان ، محمد ( • 199) : " موسوعة العاب القوى " ، دار القلم للنشر ، الكويت.

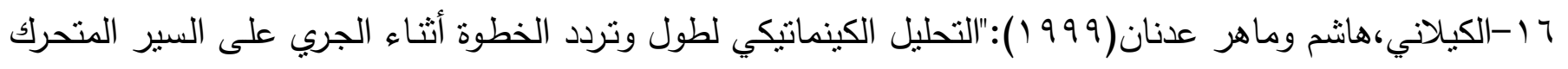
مختلف المستوى والسرعة"،بحث منشور في قسم التربية الرياضية، كلية التربية،جامعة الإمارات العربية المتحدة.

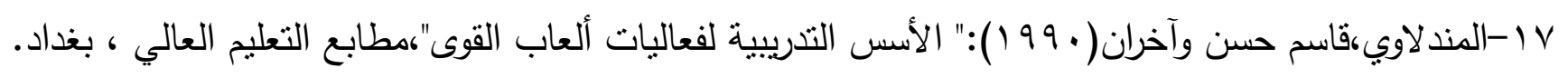

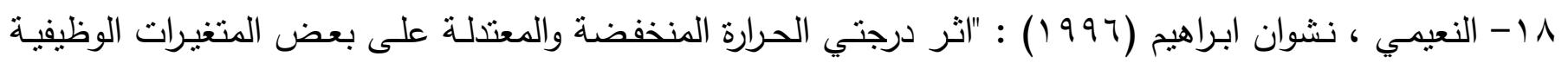

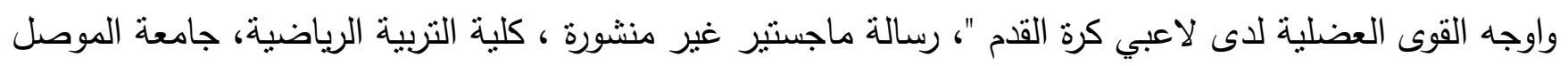
19. Clayne , R. \& Gordon, W. (1986) : “Applied Kinesiolojy and Biomechanios”, Macraw - Hill book Co., New York.

20.Costello, F. (1985): “ Training for speed using resisted and assisted methods" NSCA Journal, Vol. 7, No. (1).

21.Edington, D.W. \& Edgerton, V. R (1976) : "The Biology of physical activity " Boston, Houghtn Miffilin Co . 
22.Glaspy,S.(1964):“Soviet sprint training "in Research Quarterly, Vol. 35,No.4, December.

23.Hubiche, J. L. \& Pradet, M. (1993): “COMPRENDRE L'ATHLE'TIS”-sa pratique et son enseiqnement .

24.Johnson,C.(1982):“Success in Athletics”John Murray,Publishers, London.

25. Macardle, W. O., et. al (1981) : "Exercise Physiology, Energy" Nutration and Human Performance Lea and Febiger.

26. Maglischo, E. W (1982): “Swimming Faster”, Mayfild.

27.Modamgha, M. R. (1986): "Effects of various up hill Down hill, Combination of up hill and down hill and level training programs on sprinting speed", Unpublished thesis, Germany.

28.Nill, B. (1973): "There's speed in the hill runners world", University of Tartu.

29.Ozolin, N.G. et. al (1983) : "Loade - adaptation - adequacy - records", soviet sports review, Vol. 18, No. (4) .

30.Weineck, Ju'rgen (1997): “MANUEL D'ENTRA INEMENT" physiologie de la performance sportive ed de son de'veloppement dans l'entra inement de l'enfant de le'dolescent"'(Traduitpar) michel portman et Robert Handsch uh ,4 edition re'vise'e et augmente'e, Paris

$$
\begin{aligned}
& \text { الملحق (1) } \\
& \text { أراء السادة المتخصصين في علم التدريب الرياضي حول الصفات البدنبة الهامة في عدو .. (متر } \\
& \text { الأستاذ الفاضل ................................ } \\
& \text { السلام عليكم ورحمة الله وبركاته: } \\
& \text { يروم الباحثان بإجراء بحثهم الموسوم " أثز استخدام تدريبات السرعة بالمساعدة والمقاومة على بعض فله }
\end{aligned}
$$

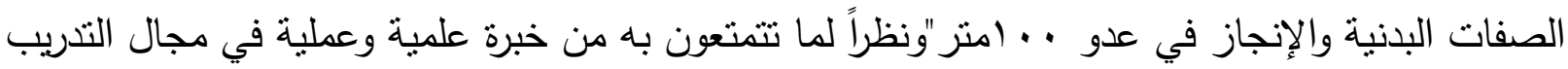

$$
\begin{aligned}
& \text { يرجى بيان رأيكم حول أهم الصفات البدنية لفعاليات العدو السريع وحسب أسبقية الأهمية. } \\
& \text { مع فائق الثكر والتقدير لشخصكم الكريم }
\end{aligned}
$$



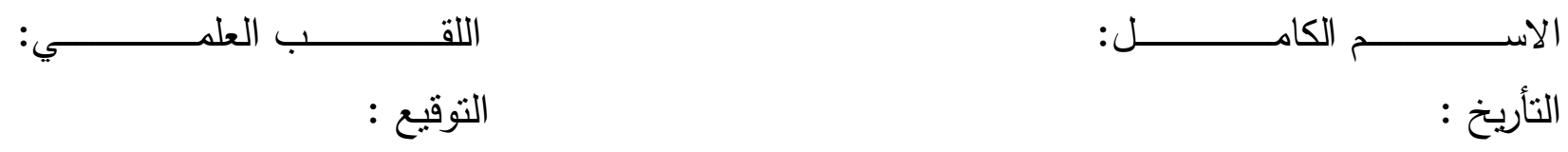

\begin{tabular}{|c|c|}
\hline تسلسل الصفة البدنية & الصفة البدنية \\
\hline & المطاولة العامة \\
\hline & مطاولة السرعة \\
\hline & مطاولة القوة لعضلات الرجلين \\
\hline & مطاولة القوة لعضلات الذراعين \\
\hline & القوة المديزة بالسرعة للرجلين \\
\hline & القوة المديزة بالسرعة للذراعين \\
\hline & القوة الانفجارية للرجلين \\
\hline & القوة الانفجارية للذراعين \\
\hline & القوة القصوى للرجلين \\
\hline & القوة القصوى للذراعين \\
\hline & سرعة رد الفعل \\
\hline
\end{tabular}

الباحثنان

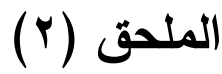

أراء السادة المتخصصين حول تحديد الاختبار الأنسب للصفات البدنية المختارة في عدو . (متز . المحترم. الأستاذ الفاضل ... السادة المنغ

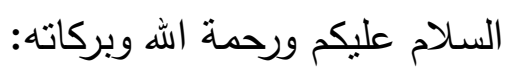

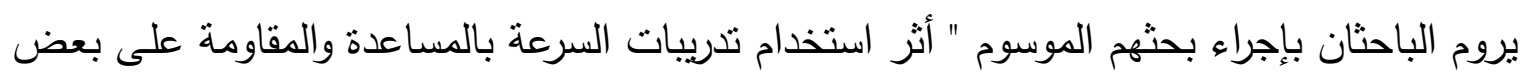

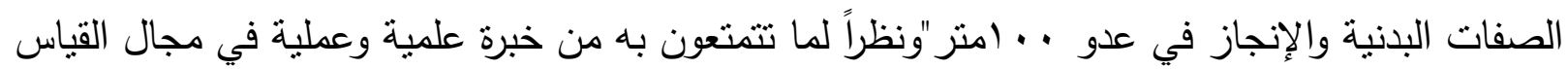
والثقويم يرجى بيان رأيكم حول تحديد الاختبار الأنسب للصفات البدنية المختارة في عدو ل. (متر .

\section{IYE}


مع فائق الثكر والتقدير لثخصم الكريم
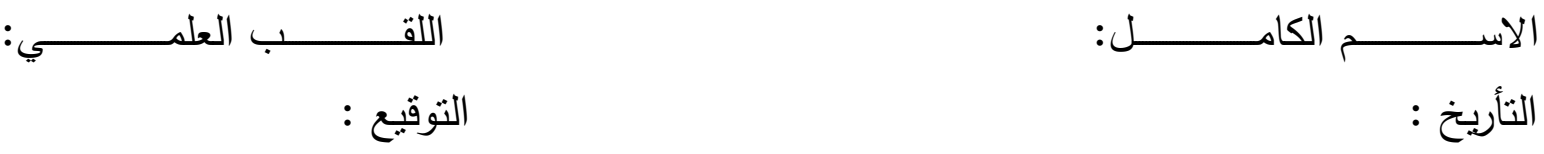

\begin{tabular}{|c|c|c|}
\hline الاختيار & 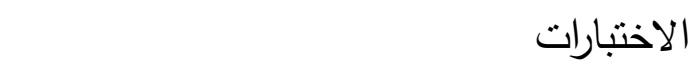 & الصفات البدنية \\
\hline & 1-العدو في المكان لـ(0) ثانية. & \multirow{4}{*}{ القوة المميزة بالسرعة } \\
\hline & r-ثلاث حجلات بالقدمين بوقت . & \\
\hline & r-الوثب الطويل إلى الأمام لـ(· r)ثانية. & \\
\hline & ع -القفز العمودي لمدة (• (1) ثانية. & \\
\hline & 1-اختبار عدو ـ متز من وضع الوقوف . & \multirow{3}{*}{ السرعة الإنتقالية القصوى } \\
\hline & ץ-اختبار عدو · •ـ متر من وضع الوقوف . & \\
\hline & r- اختبار عدو · ب متز من وضع الوقوف . & \\
\hline & 1-القفز العمودي • & \multirow{4}{*}{ القوة الانفجارية } \\
\hline & ץ- الققز العمودي لسيرجنت. & \\
\hline & س- الوثب الطويل من الثبات. & \\
\hline & ع - الوثب الطويل & \\
\hline
\end{tabular}

الباحثنان

الملحق (r)

أراء السادة المتخصصين في علم التدريب الرياضي حول البرامج التدريبية المقترحة لتدريبات السرعة بالمساعدة والمقاومة

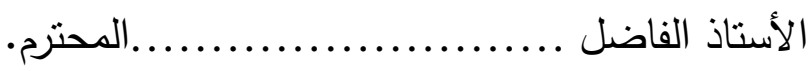

السلام عليكم ورحمة الله وبركاته

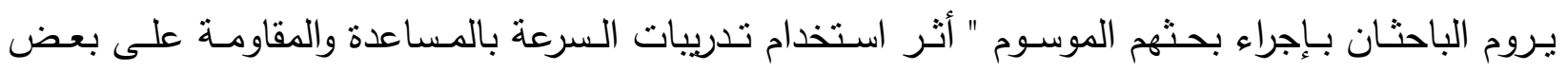
الصفات البدنية والإنجاز في عدو . (متر" ويهدف البحث الى الكشف عن أثر استخدام تدريبات السرعة 
بالمساعدة وتدريبات السرعة بالمقاومـة وتدريبات السرعة بالمساعدة والمقاومـة معاً على بعض الصفات البدنية والإنجاز في عدو · . (مثر والكثف عن دلالة الفروق الإحصائية في بعض الصفات البدنية والإنجاز في عدو • . . متر بين تدربيات السرعة بالمساعدة والمقاومة و (المساعدة والمقاومسة معاً))ونظراً لما تتمتعون بـه من خبرة علمية وعملية في مجال التدريب الرياضي يرجى بيان رأيكم حول مدى صلاحية البرامج التدريبية المقترحة لقياس الغرض الذي وضع من أجله وإبداء كافة الملاحظات التي ترونها هامة لتطوير العدو السريع •

$$
\text { مع فائق الثكر والتقدير لشخصكم الكريم }
$$
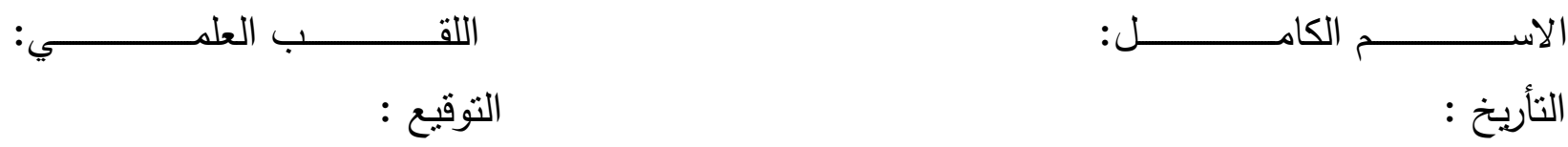

الباحثنان 